\title{
The S1 protein of SARS-CoV-2 crosses the blood-brain barrier in mice
}

\author{
Elizabeth M. Rhea, ${ }^{1,2}$, Aric F. Logsdon ${ }^{1,2}$, Kim M. Hansen ${ }^{1,2}$, Lindsey M. Williams $\mathbb{D}^{1}$, \\ May J. Reed², Kristen K. Baumann', Sarah J. Holden³, Jacob Raber ${ }^{3,4}$, William A. Banks ${ }^{1,2} \bowtie$ and \\ Michelle A. Erickson ${ }^{1,2}$
}

It is unclear whether severe acute respiratory syndrome coronavirus 2, which causes coronavirus disease 2019, can enter the brain. Severe acute respiratory syndrome coronavirus 2 binds to cells via the $\mathbf{S 1}$ subunit of its spike protein. We show that intravenously injected radioiodinated S1 (I-S1) readily crossed the blood-brain barrier in male mice, was taken up by brain regions and entered the parenchymal brain space. I-S1 was also taken up by the lung, spleen, kidney and liver. Intranasally administered I-S1 also entered the brain, although at levels roughly ten times lower than after intravenous administration. APOE genotype and sex did not affect whole-brain I-S1 uptake but had variable effects on uptake by the olfactory bulb, liver, spleen and kidney. I-S1 uptake in the hippocampus and olfactory bulb was reduced by lipopolysaccharide-induced inflammation. Mechanistic studies indicated that I-S1 crosses the blood-brain barrier by adsorptive transcytosis and that murine angiotensin-converting enzyme 2 is involved in brain and lung uptake, but not in kidney, liver or spleen uptake.

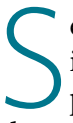
evere acute respiratory syndrome coronavirus 2 (SARS-CoV-2) is responsible for the coronavirus disease 2019 (COVID-19) pandemic. In addition to pneumonia and acute respiratory distress, COVID-19 is associated with a host of symptoms that relate to the CNS, including loss of taste and smell, headaches, twitching, seizures, confusion, vision impairment, nerve pain, dizziness, impaired consciousness, nausea and vomiting, hemiplegia, ataxia, stroke and cerebral hemorrhage ${ }^{1,2}$. It has been postulated that some of the symptoms of COVID-19 may be due to direct actions of the virus on the CNS; for example, respiratory symptoms could be in part due to SARS-CoV-2 invading the respiratory centers of the brain ${ }^{1,3}$. Encephalitis has also been reported in COVID-19, and could be a result of virus or viral proteins having entered the brain $^{4,5}$. SARS-CoV-2 mRNA has been recovered from the cerebrospinal fluid ${ }^{4}$, suggesting it can cross the blood-brain barrier (BBB). Other coronaviruses, including the closely related SARS virus that caused the 2003-2004 outbreak, are able to cross the $\mathrm{BBB}^{6-8}$, and SARS-CoV-2 can infect neurons in a BrainSphere model ${ }^{9}$. However, SARS-CoV-2 could induce changes in the CNS without directly crossing the BBB, as COVID-19 is associated with a cytokine storm, and many cytokines cross the BBB to affect CNS function ${ }^{10}$.

Here we assess whether one viral protein of SARS-CoV-2, the spike 1 protein $(\mathrm{S} 1)$, can cross the BBB. This question is important and clinically relevant for two reasons. First, some proteins shed from viruses have been shown to cross the BBB, inducing neuroinflammation and otherwise impairing CNS functions ${ }^{11-17}$. Second, the viral protein that binds to cells can be used to model the activity of the virus; in other words, if the viral binding protein crosses the $\mathrm{BBB}$, it is likely that protein enables the virus to cross the BBB as well ${ }^{18,19}$. S1 is the binding protein for SARS-CoV-2 (ref. ${ }^{20}$ ); it binds to angiotensin-converting enzyme $2(\mathrm{ACE} 2)^{21-23}$ and probably other proteins as well.
In this study, we show that I-S1 readily crossed the murine BBB, entered the parenchymal tissue of the brain and, to a lesser degree, was sequestered by brain endothelial cells and associated with the brain capillary glycocalyx. We describe I-S1 rate of entry into the brain after intravenous (i.v.) and intranasal administration, determine its uptake in 11 different brain regions, examine the effect of inflammation, APOE genotype and sex on I-S1 transport, and compare I-S1 uptake in the brain to the uptake in the liver, kidney, spleen and lung. Based on experiments with the glycoprotein WGA, we found that brain entry of I-S1 likely involves the vesicular-dependent mechanism of adsorptive transcytosis.

\section{Results}

I-S1 protein is transported across the mouse blood-brain barrier. We obtained S1 proteins from two commercial sources: RayBiotech and AMSBIO. The S1 proteins were radiolabeled in-house, and verified to be intact after labeling by autoradiography gels (Extended Data Fig. 1 and Supplementary Fig. 1). We determined whether intravenously injected I-S1 could cross the BBB in mice, by measuring its blood-to-brain influx constant $\left(K_{\mathrm{i}}\right)$ using multiple-time regression analysis (MTRA). MTRA plots the tissue/serum ratios for I-S1 against exposure time, which is a measure of time that has been corrected for the clearance of I-S1 from blood. The slope of the linear portion of this plot measures $K_{\mathrm{i}}$, that is, the unidirectional influx constant for I-S1.

We co-injected ${ }^{99 \mathrm{~m} T c}$-labeled albumin (T-Alb) along with the I-S1. T-Alb crosses the intact BBB poorly and so can be used to measure the vascular space of the brain. Any brain/serum ratios for I-S1 that exceed the brain/serum ratios of T-Alb therefore represent extravascular I-S1; that is, material which has crossed the BBB. T-Alb can also be used to measure the leakiness of peripheral tissue beds and of a BBB that has been disrupted by disease or inflammation. 


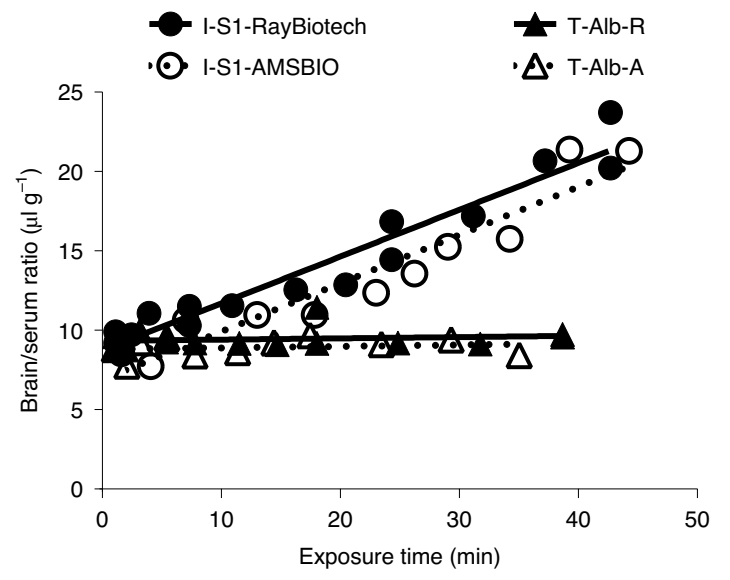

\begin{tabular}{|l|l|l|l|}
\hline & $K_{\mathrm{i}}\left(\mu \mathrm{g} \mathrm{g}^{-1} \mathrm{~min}^{-1}\right)$ & $V_{\mathrm{i}}(\mu \mathrm{l} \mathrm{g})$ & $r^{-1}$ \\
\hline I-S1 (RayBiotech) & $0.295 \pm 0.022$ & $8.74 \pm 0.50$ & 0.935 \\
\hline I-S1 (AMSBIO) & $0.304 \pm 0.033$ & $6.88 \pm 0.84$ & 0.905 \\
\hline T-Alb (RayBiotech) & $0.00800 \pm 0.0134$ & $9.332 \pm 0.263$ & 0.0266 \\
\hline T-Alb (AMSBIO) & $0.00941 \pm 0.0164$ & $8.798 \pm 0.287$ & 0.0355 \\
\hline
\end{tabular}

Fig. 1| S1 proteins from two commercial sources, RayBiotech and AMSBIO, are transported across the mouse BBB. The brain/serum ratios of I-S1 from RayBiotech and AMSBIO and T-Alb that was co-injected with I-S1-RayBiotech or I-S1-AMSBIO are plotted against exposure time. The slopes of the lines represent the $K_{\mathrm{i}}$ value of each compound in $\mu \mathrm{g} \mathrm{g}^{-1} \mathrm{~min}^{-1}$ (Methods). The $y$-axis intercept $\left(V_{i}\right)$ of each compound reflects the vascular space in $\mu \mathrm{g}^{-1}$. The $K_{\mathrm{i}}$ and $V_{\mathrm{i}}$ values (mean \pm s.e.) were calculated by simple linear regression. The $K_{\mathrm{i}}$ for I-S1 (RayBiotech) was significantly non-zero $(P<0.0001)$, indicating that there was brain uptake. The $K_{\mathrm{i}}$ for I-S1 (AMSBIO) was also significantly non-zero $(P<0.0001)$. Statistical comparisons of I-S1 curves from each vendor showed no statistical difference between the $K_{\mathrm{i}}$ values $(F(1,22)=0.05881, P=0.8106)$ but did show a difference between the $V_{i}$ values $(F(1,23)=10.32, P=0.0039)$. The $K_{\mathrm{i}}$ for T-Alb-R did not significantly deviate from zero $(P=0.3556)$, indicating that there was no brain uptake. The $K_{\mathrm{i}}$ value for T-Alb-A also did not significantly deviate from zero $(P=0.5792)$. The apparent lack of T-Alb brain uptake indicates that T-Alb remained confined to the vascular space and did not leak.

The $K_{\mathrm{i}}$ values of the I-SI proteins from the two sources differed by about 3\% (Fig. 1). These results show that unlike T-Alb, I-S1 readily crosses the mouse $\mathrm{BBB}$.

I-S1 is cleared from blood and taken up by peripheral tissues. We determined the clearance of intravenously injected I-S1 from RayBiotech from blood and its uptake in brain and other tissues, again using MTRA (Fig. 2). Clearance of I-S1 from blood was linear for the first $10 \mathrm{~min}$, with a half-time clearance of about $6.6 \mathrm{~min}$ (Fig. 2a), followed by a plateau. In Fig. 2 and subsequent figures, tissue/serum ratios for T-Alb were subtracted from the tissue/serum ratios for I-S1. These 'delta' tissue/serum ratios were thus corrected for the I-S1 in the vascular space and for any I-S1 that would have entered tissue because of a leaky capillary bed. The resulting delta values thus represent specific uptake of I-S1 by the tissues.

All tissues showed uptake of I-S1 (Fig. 2b-f). Spleen and liver uptake was nonlinear, suggesting that their tissue beds were coming into equilibrium with blood. Most substances in blood are cleared by kidney or liver; the much higher I-S1 uptake in liver compared to kidney suggests that I-S1 is cleared from blood predominantly by the liver. To determine if there were regional differences in I-S1 uptake within the brain, we collected the olfactory bulb and dissected the whole brain into ten regions (Extended Data Fig. 2). We found that I-S1 entered all brain regions, with no statistically significant differences among them.

We similarly determined the clearance of I-S1 (AMSBIO) from blood and its uptake by brain and other tissues (Fig. 3). The results were similar to those obtained with I-S1 derived from RayBiotech (Fig. 2), but there were a few differences. The AMSBIO-derived I-S1 was cleared from blood faster (half-life of $3.6 \mathrm{~min}$ ), and the rate of liver uptake was nearly five times faster than liver uptake of RayBiotech-derived I-S1 $(P<0.0001)$. Together, these results show that I-S1 is cleared from blood primarily by the liver and that $\mathrm{S} 1$ has access to other tissues relevant to COVID-19, including kidney, lung and spleen.

I-S1 is stable in brain and blood. We measured the stability of intravenously injected I-S1 from RayBiotech in blood and brain through acid precipitation (Supplementary Table 1). I-S1 added to tissues (processing controls) ex vivo showed little degradation. Radioactivity recovered from brain $10 \mathrm{~min}$ after i.v. injection and serum 10 and $30 \mathrm{~min}$ after the i.v. injection of I-S1 was stable, with most of the radioactivity precipitated by acid. Radioactivity recovered from brain $30 \mathrm{~min}$ after the i.v. injection of I-S1 was mostly degraded. This indicates that I-S1 enters the BBB intact but is eventually degraded in the brain, although it is not clear whether this involves cleavage of the radioactive iodine from I-S1 and/or whether S1 protein itself is degraded.

Most of the I-S1 taken up by the capillary bed enters the brain parenchyma. In rare cases, substances that seem to cross the $\mathrm{BBB}$ are actually sequestered by the capillary bed, which prevents them from entering the brain parenchymal/interstitial fluid space. Therefore, we next assessed whether intravenously injected I-S1 fully crosses the capillary wall to enter brain parenchyma. For this, we used a modified version of the 'capillary depletion' method that also enabled us to measure the amount of intravenously injected I-S1 that reversibly adheres to the luminal side of the capillary bed. We found that binding of I-S1 to the luminal side remained static over time, whereas there was a small increase over time in the amount of I-S1 retained by brain capillaries (Extended Data Fig. 3). The largest change over time was in the amount of I-S1 entering the parenchyma. These results show that by $30 \mathrm{~min}$, over $50 \%$ of I-S1 had crossed the capillary wall fully to enter into the brain parenchymal and interstitial fluid spaces.

WGA enhances I-S1 uptake in brain and some peripheral tissues. Wheatgerm agglutinin (WGA) is a plant lectin that crosses the $\mathrm{BBB}$ through adsorptive transcytosi ${ }^{24}$ - a process by which proteins or peptides bind to glycoproteins of the luminal surface of endothelial cells, are internalized into vesicles, and then transported across the membrane. For WGA, adsorptive transcytosis occurs when WGA binds to cell-surface glycoproteins containing sialic acid and $N$-acetylglucosamine. Many viral proteins also bind to glycoproteins containing sialic acid and $\mathrm{N}$-acetylglucosamine, and therefore, when WGA is co-injected with such viral proteins, it enhances their transport across the BBB and uptake in peripheral tissues ${ }^{18}$. Here, we found that uptake of intravenously injected I-S1 (RayBiotech or AMSBIO) into brain, lung, spleen and kidney was increased when WGA was included in the injection (Fig. 4b-e). WGA co-injection also increased clearance of I-S1 (RayBiotech), but not I-S1 (AMSBIO), as shown by a decrease in I-S1 in blood (Fig. 4a). WGA co-injection decreased uptake of I-S1 (AMSBIO) but not I-S1 (RayBiotech) in the liver (Fig. 4f), although it did decrease I-S1 (RayBiotech) uptake in liver in another experiment (see below and Fig. 4h).

These results strongly suggest that I-S1 crosses the BBB and peripheral tissue beds through the mechanism of adsorptive 
S1 glycoprotein (RayBiotech)
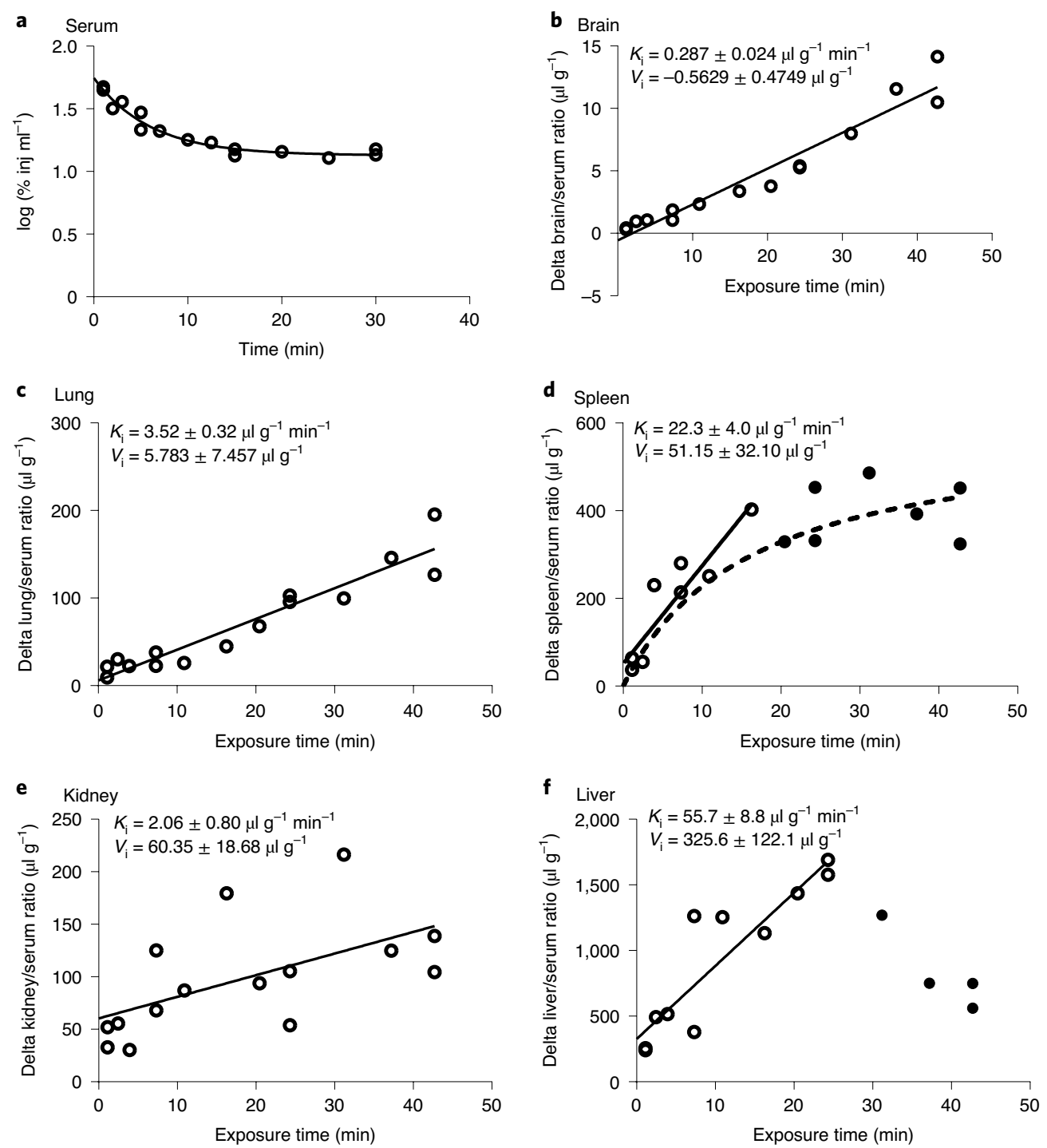

Fig. 2 | I-S1 (RayBiotech) is cleared from blood and taken up by peripheral tissues. a, Clearance of I-S1 (RayBiotech) from blood. Data were fitted to a nonlinear one-phase exponential decay model: $y=0.617\left(\mathrm{e}^{-0.165 t}\right)+1.13$ with a half-life of $4.20 \mathrm{~min}\left(n=15\right.$ mice; $\left.r^{2}=0.956\right)$. Clearance from blood was linear for the first $10 \mathrm{~min}$, with a half-time clearance of $6.6 \mathrm{~min}$. b-f, The y axes show the delta tissue/serum ratios for I-S1, corrected for vascular space and non-specific leakage (Methods). $\mathbf{b}$, The I-S1 $K_{\mathrm{i}}$ value for whole brain was significantly non-zero $(P<0.0001)$, indicating that there was tissue uptake $\left(n=15\right.$ mice). c-f, The I-S1 $K_{\mathrm{i}}$ values for different tissues calculated based on the linear portions of their curves. c, The I-S1 $K_{\mathrm{i}}$ value for lung was significantly non-zero $\left(P<0.0001 ; n=15\right.$ mice). d, The I-S1 $K_{\mathrm{i}}$ value for spleen was significantly non-zero $(P=0.0014 ; n=8$ mice; $n=7$ mice (filled circles) were excluded from the regression analysis due to nonlinearity, which violates assumptions of MTRA). e, The I-S1 $K_{\mathrm{i}}$ value for kidney was significantly non-zero $\left(P=0.024 ; n=15\right.$ mice). $\mathbf{f}$, The I-S1 $K_{\mathrm{i}}$ value for liver was significantly non-zero $(P=0.0001 ; n=11$ mice; $n=4$ mice (filled circles) were excluded from regression analysis due to nonlinearity). All error terms are the s.e.m.

transcytosis, binding to cell-surface glycoproteins that contain sialic acid or $N$-acetylglucosamine.

Heparin blocks uptake of I-S1 in liver but not in brain. Some viruses use heparan sulfate on the cell membrane as a receptor ${ }^{25}$. Heparin can block virus uptake in tissues, presumably by binding to viral proteins and thereby blocking these viral proteins from binding to the heparan sulfate on the cell membranes ${ }^{19,26}$. However, we found that heparin co-injected with I-S1 did not affect uptake of I-S1 (RayBiotech) in brain, lung, spleen or kidney and did not influence the effect of WGA co-injection on I-S1 uptake in these tissues (data not shown). Heparin co-injected with I-S1 did block uptake of I-S1 in liver (Fig. 4h), which likely explained the observed decreased clearance of I-S1 from blood (as evidenced by the increase in I-S1 levels in serum; Fig. 4g), but it did not block the effect of WGA on I-S1 uptake in liver. These results indicate that I-S1 uses heparin-sensitive sites to bind to the capillary bed of the liver, but not to bind to the capillary beds of brain, spleen, lung or kidney.

I-S1 uptake in brain was not blocked by unlabeled S1. We next determined whether transport of intravenously injected I-S1 (RayBiotech) into the brain could be blocked by including in the injection an excess of unlabeled S1 protein (AMSBIO). Unlabeled S1 did not affect brain/serum ratios for delta I-S1 at any of the tested doses (Fig. 5a), although it did enhance uptake of I-S1 in lung (Fig. 5c). This indicates that the binding site for I-S1 in brain tissue is not 
S1 glycoprotein (AMSBIO)
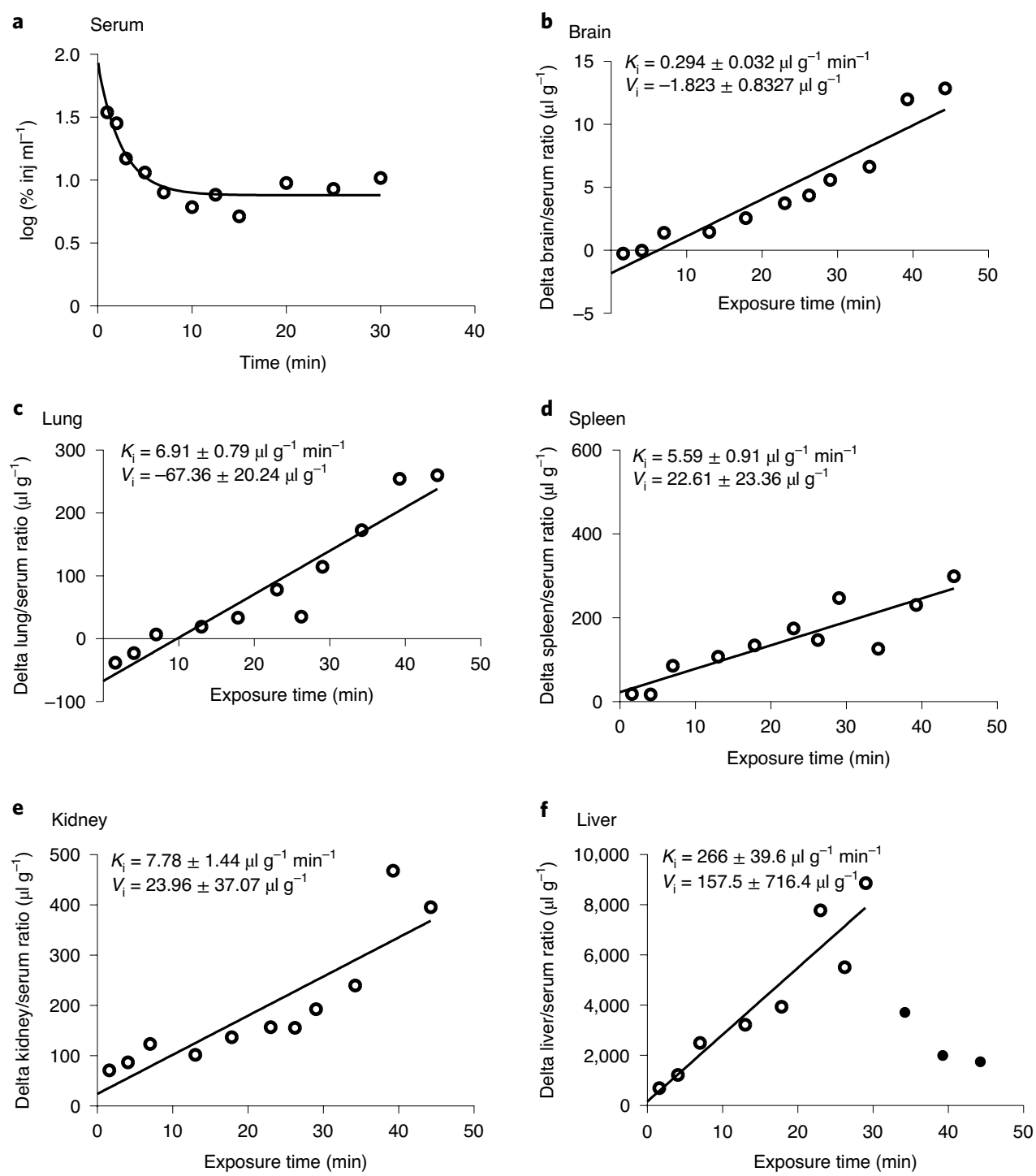

Fig. 3 | I-S1 (AMSBIO) is cleared from blood and taken up by peripheral tissues. a, Clearance of I-S1 from AMSBIO from blood. Data were fitted to a one-phase exponential decay model: $y=1.05\left(e^{-0.393 t}\right)+0.880$ (half-life of $1.74 \mathrm{~min} ; n=11$ mice; $r^{2}=0.867$ ). Clearance from blood was linear for the first $10 \mathrm{~min}$, with a half-time clearance of $3.6 \mathrm{~min}$. In $\mathbf{b}$-f, the $y$ axes show the delta tissue/serum ratios for I-S1, corrected for vascular space and nonspecific leakage (Methods). b, The I-S1 $K_{\mathrm{i}}$ value for whole brain was significantly non-zero $(P<0.0001)$, indicating tissue uptake $\left(n=11\right.$ mice). $\mathbf{c}-\mathbf{f}$, The I-S1 $K_{\mathrm{i}}$ values for different tissues calculated based on the linear portions of their curves. $\mathbf{c}$, The I-S1 $K_{\mathrm{i}}$ for lung was significantly non-zero $(P<0.0001 ; n=11$ mice $)$. d, The I-S1 $K_{\mathrm{i}}$ value for spleen was significantly non-zero $\left(P=0.002 ; n=11\right.$ mice). e, The I-S1 $K_{\mathrm{i}}$ value for kidney was significantly non-zero $(P=0.0004$; $n=11$ mice). $\mathbf{f}$, The I-S1 $K_{\mathrm{i}}$ for liver was significantly non-zero $(P=0.0005 ; n=8$ mice; $n=3$ mice (filled circles) were excluded from regression analysis due to nonlinearity). All error terms are the s.e.m.

easily saturated-a characteristic of adsorptive transcytosis. Unlabeled S1 also did not affect brain/serum ratios for T-Alb (data not shown), which indicates that even the high dose $(10 \mu \mathrm{g})$ of $\mathrm{S} 1$ did not acutely disrupt the BBB.

ACE2 likely mediates I-S1 uptake in brain and lung but not other tissues. The ability of SARS-CoV-2 to enter cells is thought to depend on the $S$ protein binding to the membrane-bound enzyme (and glycoprotein) ACE2. To assess whether ACE2 has a role in I-S1 uptake in brain and peripheral tissues, we intravenously co-injected human ACE2 or the ACE2 substrates Ang II and ghrelin with I-S1 (RayBiotech). This did not affect blood levels of intravenously injected I-S1 or T-Alb (data not shown), indicating that these proteins did not affect the volume of distribution or clearance of either S1 or albumin. Co-injection of ACE2 increased kidney levels of intravenously injected T-Alb: $F(4,36)=2.63, P=0.0505$; vehicle: $119 \pm 4.4 \mu \mathrm{l} \mathrm{g}^{-1}(n=8$ mice $)$ ACE2: $151 \pm 15.6 \mu \mathrm{l} \mathrm{g}^{-1}(n=8$ mice), $P=0.02$ ), possibly indicating that ACE2 affects renal clearance of albumin. Only ACE2 co-injection enhanced I-S1 uptake in brain (Fig. 5b). Uptake in lung was increased by co-injection of S1, ghrelin or ACE2, but not angiotensin II (Fig. 5c), whereas uptake in liver, kidney or spleen was not altered by co-injection of any of these substances (data not shown). These results suggest that ACE2 is involved in S1 uptake in lung and probably brain, but not in I-S1 uptake in spleen, liver or kidney.

Inflammation increases I-S1 uptake in brain and lung. Since SARS-CoV-2 infection induces an inflammatory state, we next 

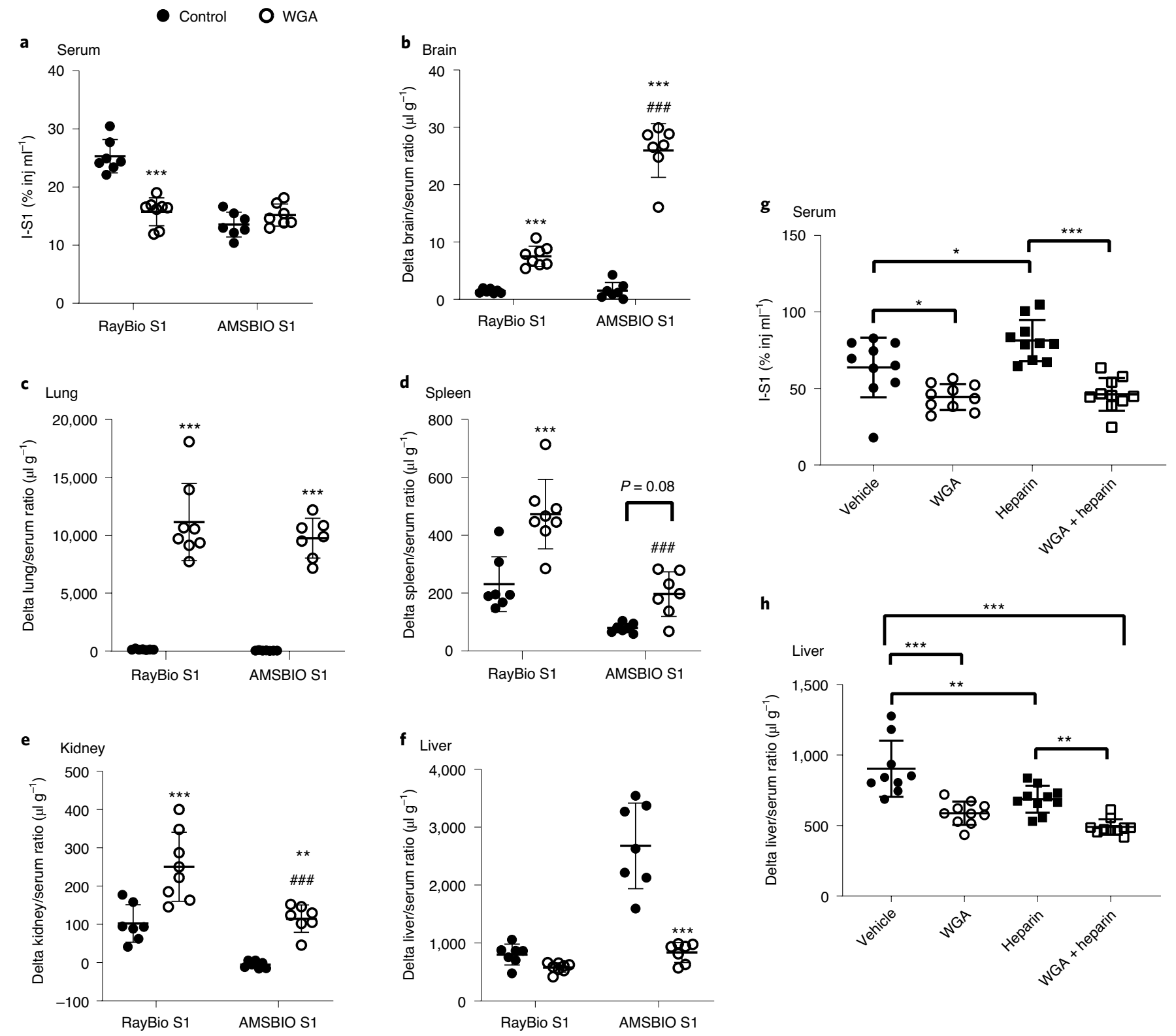

Fig. 4 | WGA enhances I-S1 uptake by brain, lung, spleen and kidney, while heparin blocks uptake by liver. a-f, Serum levels and tissue uptake of I-S1 from either RayBiotech or AMSBIO 10 min after i.v. injection in which WGA, a stimulator of adsorptive transcytosis, was included in the injections to half of the mice. a, Serum I-S1 levels expressed as the percentage of the injected dose per $\mathrm{ml}$ of serum. There was a main effect of $\mathrm{S1}$ source $(F(1,25)=49.79$, $P<0.0001)$ and treatment $(F(1,25)=20.57, P<0.0001)$, as well as a significant effect of their interaction $(F(1,25)=40.93, P<0.0001)$. WGA treatment decreased I-S1 (RayBiotech) levels in serum $(P<0.0001)$, indicating increased clearance from blood. $\mathbf{b}$, Brain I-S1 levels expressed as delta brain/serum ratios, showing significant effects (all $P<0.0001$ ) of $S 1$ source $(F(1,25)=92.98$ ), treatment $(F(1,25)=252.2)$ and their interaction $(F(1,25)=91.41)$. These results show that WGA stimulated I-S1 uptake from both RayBiotech and AMSBIO and that WGA stimulated uptake of I-S1 from AMSBIO more than from RayBiotech. c, Lung I-S1 levels show an effect of treatment $(F(1,25)=204.6, P<0.0001)$. d, Spleen I-S1 levels show effects of $S 1$ source $(F(1,25)=43.06$, $P<0.0001)$ and treatment $(F(1,25)=30.42, P<0.0001)$ and a trend for interaction $(F(1,25)=3.657, P=0.08)$. e, Kidney I-S1 levels show effects of source $(F(1,25)=33.45, P<0.0001)$ and treatment $(F(1,25)=40.77, P<0.0001)$. f, Liver I-S1 levels show effects of source of $S 1(F(1,25)=55.87)$, treatment $(F(1,25)=52.16)$ and their interaction $(F(1,25)=32.08)$, all at $P<0.0001$. For a-f, data were analyzed using two-way ANOVA with S1 source (RayBiotech versus AMSBIO) and treatment (with or without WGA) as main factors, followed by Tukey's multiple-comparisons tests; data are the mean

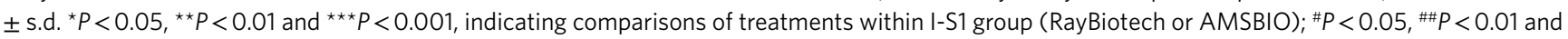
$\# \# P<0.001$, indicating comparisons of I-S1 groups within treatments. $n=7$ per group, except for RayBiotech S1-WGA mice $(n=8)$. g,h, Serum levels and liver uptake of I-S1 from RayBiotech 10 min after i.v. injection with or without co-injection of WGA, heparin or both. $\mathbf{g}$, Heparin increased serum levels of I-S1 $(P=0.016)$, but did not block the effect of WGA on I-S1 serum levels. $\mathbf{h}$, In comparison to vehicle, uptake of I-S1 was decreased by heparin $(P=0.0015), W G A(P<0.0001)$ and WGA + heparin $(P<0.001)$. Liver uptake of I-S1 was lower after WGA + heparin versus heparin alone $(P=0.0034)$ but not versus WGA alone. ${ }^{\star} P<0.05$, ${ }^{\star \star} P<0.01$ and ${ }^{\star \star \star} P<0.001$. For $\mathbf{g}$ and $\mathbf{h}$, data were analyzed by one-way ANOVA and Sidak's multiple-comparisons test, with $n=10$ for each group, with the exception of liver vehicle in $\mathbf{h}$, where one outlier was identified using a Grubbs test $\left(77.6 \mu l \mathrm{~g}^{-1}\right)$ and excluded, leaving $n=9$ mice. 

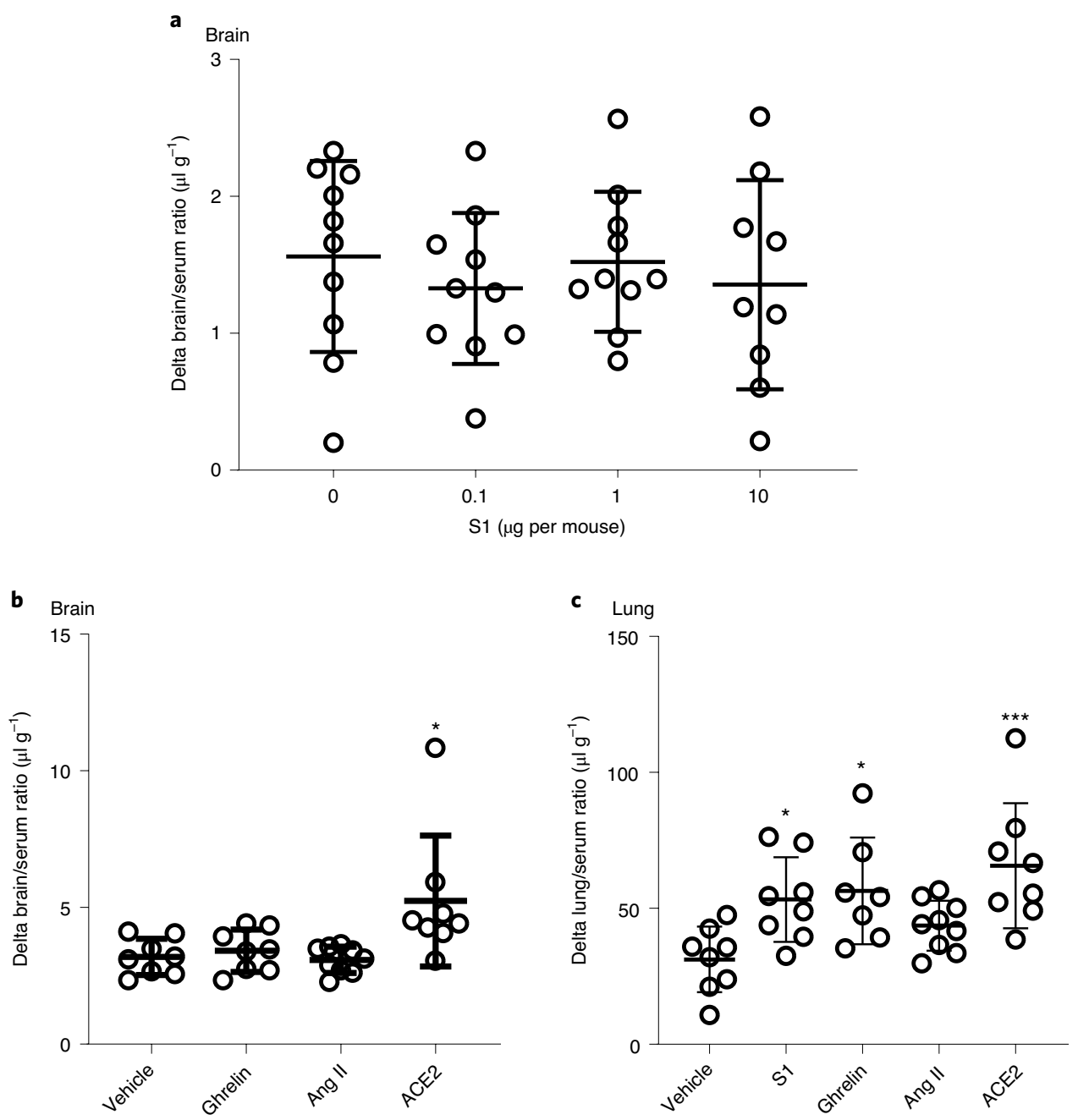

Fig. 5 | Effects of unlabeled S1, ACE2 and ACE2 substrates on I-S1 uptake into tissues. a-c, Tissue uptake of I-S1 from RayBiotech 10 min after i.v. injection with or without unlabeled S1 (from AMSBIO), ACE2 or the ACE2 substrates ghrelin or angiotensin II (Ang II). The $y$ axis shows the albumin-corrected (delta) tissue/serum ratio. Data are the mean \pm s.d. a, Unlabeled S1 at a dose of $0.1 \mu \mathrm{g}(n=10$ mice $), 1 \mu \mathrm{g}(n=10)$ or $10 \mu \mathrm{g}(n=9)$ did not reduce brain I-S1 uptake compared to vehicle controls $(n=10$; one-way ANOVA: $F(3,33)=0.6312, P=0.6)$. b. Co-injection had a significant main effect on brain I-S1 uptake (one-way ANOVA: $F(3,29)=4.7, P=0.0073$ ), with $1 \mu$ g of ACE2 increasing uptake (ACE2 versus vehicle: $P=0.0109$; Dunnett's multiple-comparisons test) but no effect of $1 \mu \mathrm{g}$ ghrelin or $1 \mu \mathrm{g}$ Ang II. ( ${ }^{\star} P<0.05 ; n=8,8,9$ and 8 for the vehicle, ghrelin, Ang II and ACE2 groups, respectively). c, Co-injection had a significant main effect on lung I-S1 uptake (one-way ANOVA: $F(4,35)=5.12, P=0.0023$ ), with significant effects of $1 \mu \mathrm{g}$ of unlabeled $\mathrm{S} 1(P=0.0372), 1 \mu \mathrm{g}$ ghrelin $(P=0.0188)$ and $1 \mu \mathrm{g}$ ACE2 $(P=0.0007)$, but no effects of $1 \mu \mathrm{g}$ Ang $\|(P=0.3511$; all Dunnett's test $) .{ }^{\star} P<0.05,{ }^{\star \star} P<0.01$ and ${ }^{\star \star \star} P<0.001$. $n=8,8$, 7,9 and 8 for vehicle, S1, ghrelin, Ang II and ACE2, respectively. One outlier $\left(201 \mu \mathrm{I} \mathrm{g}^{-1}\right)$ in the ghrelin group was detected by a Grubbs test $(\alpha<0.05)$ and excluded from analysis.

determined whether an inflammatory state-in this case, induced by lipopolysaccharide (LPS) injection-affects uptake of intravenously injected I-S1 (RayBiotech) in brain and peripheral tissues. Mice received a $3 \mathrm{mg} \mathrm{kg}^{-1}$ injection of LPS derived from Salmonella typhimurium (Sigma) at $t=0$ and again at 6 and $24 \mathrm{~h}$ later, and received an i.v. I-S1 plus T-Alb injection $28 \mathrm{~h}$ after the first LPS injection; this LPS regimen can disrupt the $\mathrm{BBB}$, increase its permeability to viruses and viral proteins $s^{27,28}$ and increase the blood level of many of the cytokines found to be elevated in the cytokine storm associated with COVID-19 (refs. ${ }^{5,29}$ ).

We found that LPS did not affect T-Alb blood levels, indicating that inflammation did not induce volume contraction of the vascular space nor leakiness of the peripheral capillary beds in these mice. Mice that had received LPS had higher I-S1 serum levels (Fig. 6a), indicating a decrease in clearance from blood (likely because of the decreased I-S1 uptake in liver observed in these mice; Fig. 6b), as well as higher T-Alb brain/serum ratios, indicating BBB disruption (control: $8.52 \pm 0.19 \mu \mathrm{l} \mathrm{g}^{-1}(n=10)$; LPS: $12.2 \pm 0.68 \mu \mathrm{l} \mathrm{g}^{-1}(n=8)$, $t=5.74, P<0.0001)$. These mice also had higher I-S1 brain/serum ratios (that is, ratios not corrected for I-S1 in the vascular space and for any I-S1 brain entry due to leakage), indicating increased I-S1 passage across the BBB (control: $12.06 \pm 0.26 \mu \mathrm{l} \mathrm{g}^{-1}(n=10)$; LPS: $\left.14.9 \pm 0.64 \mu \mathrm{lg}^{-1}(n=8), t=4.38, P=0.0005\right)$, although their delta brain/serum ratios for I-S1 (that is, corrected ratios) were not different from controls (except in the olfactory bulb) (Fig. 6c). The only peripheral tissue showing an increased uptake of I-S1 after receiving LPS was the lung, where uptake was increased by $101 \%$ (Fig. 6b). These results show that inflammation could increase S1 toxicity for lung tissue by increasing its uptake. The results also show that, in mice, inflammation can increase entry of intravenously injected I-S1 into brain, but this is likely due to BBB disruption rather than by enhancing absorptive transcytosis. 


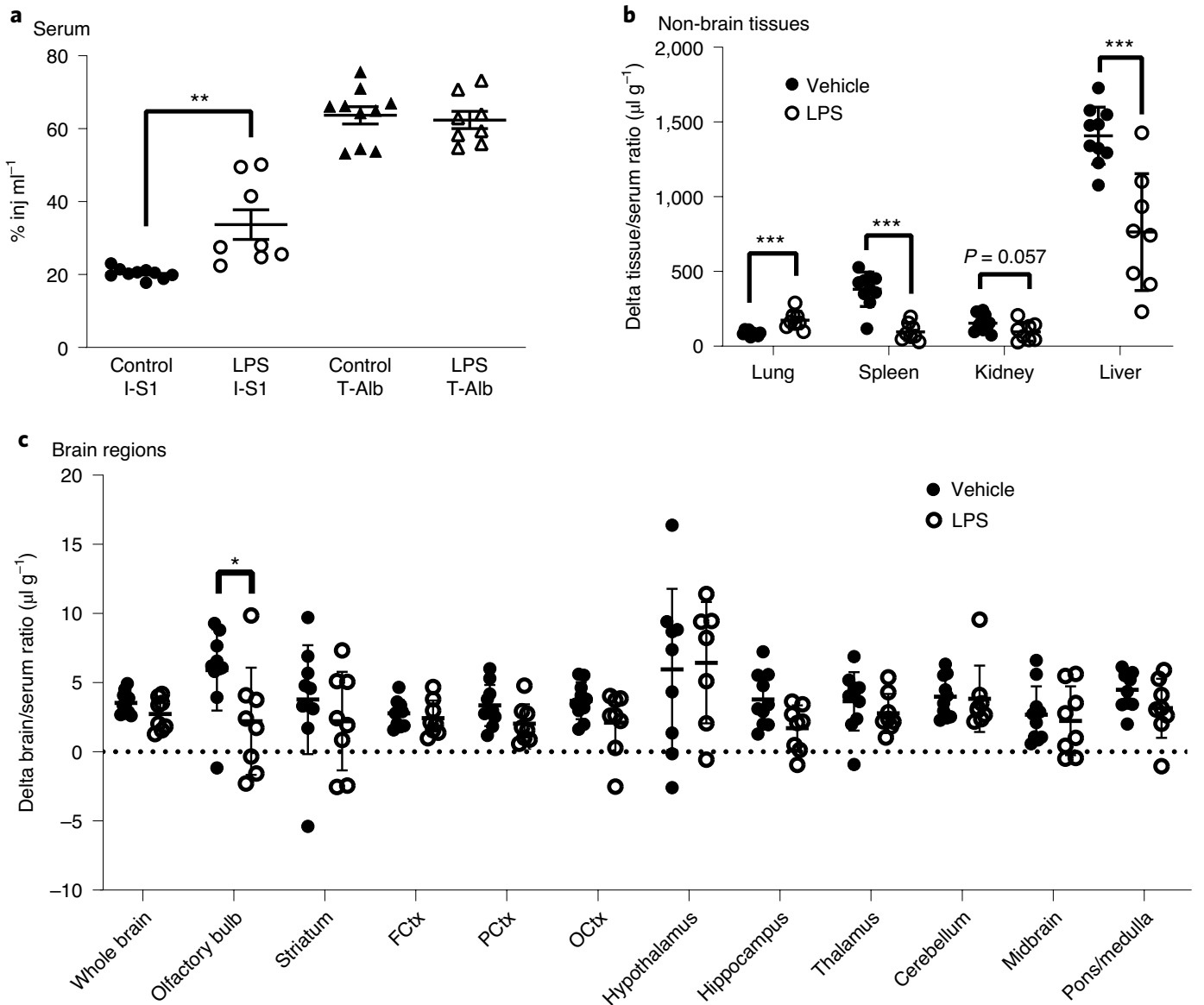

Fig. 6 | LPS has minimal effects on brain I-S1 uptake but alters I-S1 clearance from blood and uptake by peripheral tissues. a-c, We treated mice with intraperitoneal LPS using a protocol previously shown to alter BBB permeability and induce inflammation (Methods). Four hours after the last injection of LPS, we gave mice an i.v. injection containing I-S1 (RayBiotech) and T-Alb and collected tissue and blood samples 10 min after the i.v. injection. a, Serum levels of I-S1 (RayBiotech), expressed as the percentage of injected dose per $1 \mathrm{ml}\left(\%\right.$ inj $\left.\mathrm{ml}^{-1}\right)$ of serum, were increased $4 \mathrm{~h}$ after LPS injection versus control $(t=3.66, \mathrm{df}=16, P=0.0021$, two-tailed $t$-test), indicating that LPS decreased clearance of I-S1 from blood. LPS had no significant effect on the serum levels of T-Alb ( $t=0.3739, \mathrm{df}=16, P=0.7134)$, indicating a selective effect of LPS on I-S1 clearance. $\mathbf{b}$, Tissue levels of I-S1, expressed as tissue/serum ratios corrected (delta brain/tissue ratios) for vascular space and leakage by subtracting the tissue/serum ratios for T-Alb. LPS increased I-S1 uptake by lung tissue $(t=4.58, \mathrm{df}=16, P=0.0003)$ and decreased I-S1 uptake by spleen $(t=6.39, \mathrm{df}=16, P<0.0001)$ and liver $(t=4.60, \mathrm{df}=16, P=0.0003)$; the effect of LPS on I-S1 uptake by kidney was not significant ( $P=0.057$; all two-tailed $t$-tests). The decreased I-S1 uptake by liver tissue likely contributes to the decrease in I-S1 clearance from blood seen in a. c, Levels of I-S1 in brain areas, expressed as delta brain/serum ratios. Two-way ANOVA showed a significant main effect of brain region $(F(11,190)=2.72, P=0.0028)$, accounting for $12.5 \%$ of the variability, and a main effect of LPS treatment $(F(11$, $190)=10.7, P=0.0012$ ), accounting for $4.5 \%$ of the variability; there was no statistically significant effect for interaction. Sidak's multiple-comparisons test showed that LPS treatment decreased I-S1 uptake by the olfactory bulb $(P=0.026)$ but not other brain regions. ${ }^{\star} P<0.05,{ }^{\star \star} P<0.01$, ${ }^{\star \star \star} P<0.001$ and $t=0.1>P>0.05$. FCtx, frontal cortex; PCtx, parietal cortex; OCtx, occipital cortex. Data are the mean \pm s.d. Control groups (a): $n=10$ mice; vehicle group (b and $\mathbf{c}$ ): $n=10$ mice; LPS group (a-c): $n=10$ mice.

I-S1 enters mouse brain and blood after nasal administration. Some viruses can enter the brain via the olfactory nerve, a cranial nerve with projections through the cribriform plate ${ }^{30}$. Other viruses may cross the BBB after entering the bloodstream from the nasal compartment. It is unclear whether SARS-CoV-2 in the nose can enter brain by either of these routes. We therefore assessed the ability of intranasally administered I-S1 to enter the brain. Following an injection of a $1-\mu$ l vehicle solution containing I-S1 to each naris at the level of the cribriform plate (where the olfactory nerve emerges from the cranial vault), I-S1 was detected in all brain regions (Fig. 7a,b). I-S1 levels in whole brain, frontal cortex, cerebellum, midbrain and pons-medulla were higher at 30 min compared to $10 \mathrm{~min}$ after administration. I-S1 distribution in the brain was mostly homogeneous, although levels in the olfactory bulb and hypothalamus were higher than in other brain regions at $10 \mathrm{~min}$ and also in the olfactory bulb at $30 \mathrm{~min}$ after administration. Whole-brain I-S1 levels expressed as the percentage of the administered dose were about ten times higher after i.v. injection than after intranasal injection (Fig. 7a). Radioactivity appeared in blood after intranasal administration of I-S1, indicating that some I-S1 had entered the bloodstream (data not shown). The area under the curve (AUC) for I-S1 in blood after intranasal administration was $9.42\left(\%\right.$ inj $\left.\mathrm{ml}^{-1} \mathrm{~min}^{-1}\right)$, whereas the AUC for I-S1 in blood after i.v. injection was $1,430\left(\%\right.$ inj $\left.\mathrm{ml}^{-1} \mathrm{~min}^{-1}\right)$, indicating that the bioavailability for the nasal route was $0.66 \%$. Together, these results show that I-S1 can enter the brain and distribute in a time-dependent manner to all brain regions after intranasal administration. However, I-S1 uptake in the brain via this route is much less efficient than uptake after transport across the BBB. 
a Intranasal: $10 \mathrm{~min}$

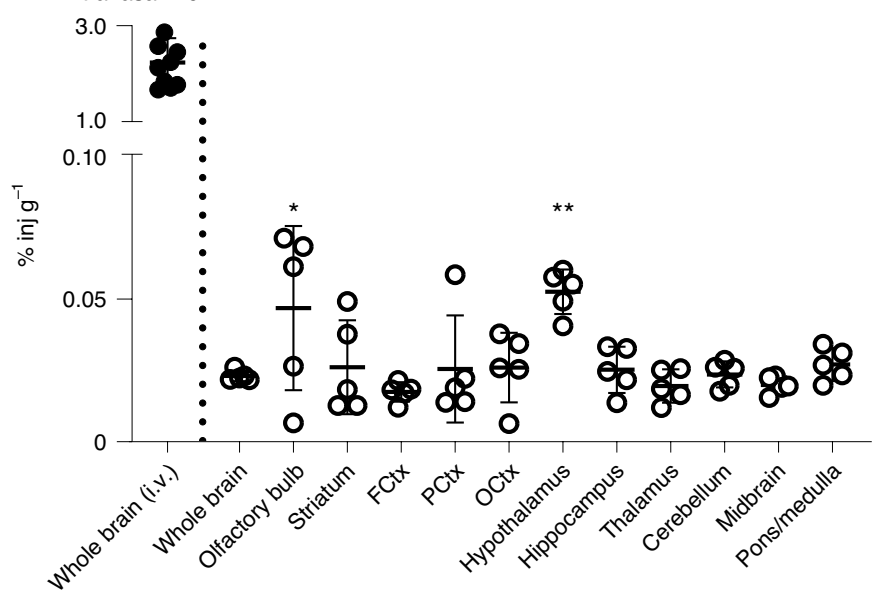

b Intranasal: $30 \mathrm{~min}$

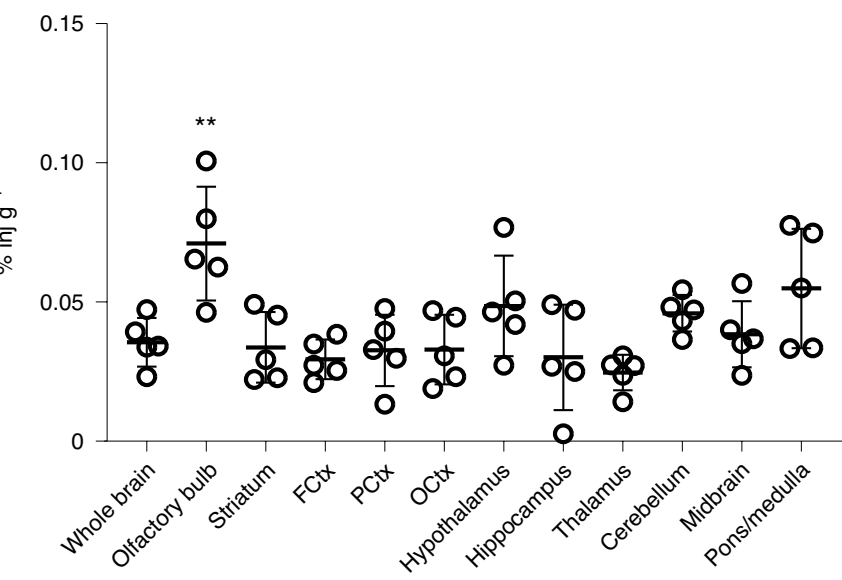

Fig. 7 | I-S1 enters the brain after intranasal administration. a,b, Brain uptake of I-S1 (RayBiotech) delivered intranasally (1 $\mu$ l per naris), expressed as the percentage administered dose taken up per gram of each brain region

(\% inj $\mathrm{g}^{-1}$ ). a, At 10 min after intranasal administration, I-S1 was detected in all dissected brain regions. One-way ANOVA showed a significant effect of brain region $(F(11,48)=3.77, P=0.0006)$, with significantly higher uptake in the olfactory bulb $(P=0.031)$ and hypothalamus $(P=0.0041)$ compared to the whole brain (Dunnett's multiple-comparisons test). Whole-brain uptake after intranasal administration was $0.023 \pm 0.0008 \%$ inj $\mathrm{g}^{-1}$; for visual comparison, we also show the whole-brain percentage dose per gram $10 \mathrm{~min}$ after i.v. injection as calculated from the control values for the LPS experiment in Fig. 6 (filled circles, $0.22 \pm 0.016 \%$ inj $g^{-1}$ ); $n=5$ mice. b. At 30 min after intranasal administration, I-S1 was detected in all dissected brain regions. One-way ANOVA showed a significant effect of brain region $(F(11,48)=4.33$, $P=0.0002)$, with significantly more uptake in the olfactory bulb compared to whole brain ( $P=0.0023$, Dunnett's multiple-comparisons test). A two-tailed $t$-test showed significant increases between 10 and $30 \mathrm{~min}$ for the whole brain $(P=0.0143, t=3.116, d f=8)$, frontal cortex $(P=0.0391, t=2.464, d f=8)$, cerebellum ( $P=0.0003, t=6.226, \mathrm{df}=8)$, midbrain $(P=0.0098, t=3.370$, $\mathrm{df}=8)$ and pons $(P=0.0232, t=2.801, \mathrm{df}=8)$ but not the other regions; $n=5$ mice. ${ }^{\star} P<0.05,{ }^{\star \star} P<0.01$ and ${ }^{\star \star \star} P<0.001$.

Effects of sex and APOE genotype on I-S1 uptake. Male sex and $A P O E 4$ genotype in comparison to the APOE3 genotype are risk factors for both contracting and having a poor outcome from COVID-19 (refs. ${ }^{31-33}$ ). Therefore, we determined uptake of intravenously injected I-S1 (RayBiotech) or T-Alb in male and female mice expressing human $A P O E 3$ or $A P O E 4$ under the expression of the mouse ApoE promoter. APOE genotype and sex did not affect T-Alb brain/serum ratios (Fig. 8a). Two-way ANOVA showed an effect of sex on I-S1 uptake in the olfactory bulb and spleen and an effect of APOE genotype on I-S1 uptake in liver, spleen and kidney (Fig. 8b-h). Multiple-comparisons tests showed that, compared to the other three groups, male mice expressing human APOE3 had the fastest I-S1 uptake of I-S1 in the olfactory bulb, liver and kidney, whereas compared to the other three groups, female mice expressing human $A P O E 3$ had the fastest I-S1 uptake in spleen. These results suggest that enhanced uptake of I-S1 by some tissues could contribute to the increased risk of COVID-19 in males versus females, but not to the risk associated with the $A P O E 4$ genotype.

I-S1 transport across an in vitro model of the BBB. To determine whether the I-S1 crosses endothelial-like cells in an in vitro model of the human BBB, we compared transport of I-S1 versus T-Alb across monolayers of human induced pluripotent stem cell (iPSC)-derived brain endothelial-like cells (iBECs) seeded on Transwells. Three independent experiments showed that rate of passage of I-S1 (RayBiotech) in the luminal-to-abluminal direction was not statistically significant when compared to that of T-Alb (Extended Data Fig. 4a). One experiment indicated that unlabeled S1 did not inhibit I-S1 (RayBiotech) passage (Extended Data Fig. 4b). WGA also had no effect on RayBiotech I-S1 transport (Extended Data Fig. 4c). I-S1 (RayBiotech) had a significantly higher permeability coefficient than I-S1 (AMSBIO I-S1) in vitro (Extended Data Fig. $4 \mathrm{~d}$ ); however, this difference was not significant after correcting for T-Alb transport. In summary, these results suggest that iBECs may be more permeable to I-S1 than to T-Alb, but the difference is too small to support mechanistic studies using this model.

\section{Discussion}

The results from this study show that I-S1 from two different commercial sources readily crosses the mouse BBB, at least when injected intravenously. I-S1 was taken up by all 11 brain regions examined. Such widespread entry into brain of I-S1 could explain the diverse effects of S1 and/or SARS-CoV-2 such as encephalitis, respiratory difficulties and anosmia ${ }^{1,3,4}$. S1 is the SARS-CoV-2 protein that initially binds to cell-surface receptors, setting the stage for viral internalization. For transport across the BBB, viral binding proteins often behave similarly to the virus itself. For example, interactions (including binding and transport) between the HIV-1 glycoprotein gp120 and the $\mathrm{BBB}$ are similar to those for the complete virus ${ }^{18,28}$. Additionally, many if not most viral proteins themselves can be biologically highly active; for example, gp120 is highly toxic ${ }^{11-17}$. Coronavirus spike proteins are often cleaved from the virus by host cell proteases. Once cleaved, coronavirus spike S1 and S2 subunits are not held covalently by disulfide bonds and so $\mathrm{S} 1$ could be shed from virions $\mathrm{s}^{34}$. It is possible that during infection by SARS-CoV-2, shed S1 is available to cross the BBB, triggering responses in the brain itself, without necessarily involving crossing of intact virus particles. Thus, determining whether S1 crosses the BBB is important for understanding whether SARS-CoV-2 and $\mathrm{S} 1$ itself could induce responses in the brain.

Our method of studying S1 pharmacokinetics has many advantages over the more traditional approach of determining viral uptake and distribution that is based on virus recovery. Radioactive labeling allows S1 to be detected at very low levels and quantification of the rates of uptake for brain and other tissues. Factors that might affect viral protein uptake can be manipulated experimentally in healthy, rather than infected, animals. Recovery of I-S1 from a tissue reflects only factors related to permeability, whereas recovery from infected mice also reflects other factors, such as rate of virus replication in that tissue.

A crucial question which we partially answered here was: what receptor does I-S1 use to enter brain and other tissues? Based on 
experience with SARS, it is assumed that SARS-CoV-2 will bind to human ACE2, but not murine ACE2. SARS can infect wild-type (WT) mice, but it doesn't produce severe symptoms and death, except in transgenic mice overexpressing human ACE2 (ref. ${ }^{35}$ ), although this could also simply be because these transgenic mice express 8-12 times more ACE2 than WT mice. The mice used here only expressed murine receptors, so our findings suggest that the assumption that ACE2 must be the human protein is incorrect and demonstrate that WT mice can be used in kinetics studies of S1 and probably SARS-CoV-2.

We did find reasonably strong evidence that murine ACE2 is involved in I-S1 uptake in lung tissue, as co-injection of I-S1 with soluble ACE2 and ACE2 substrates increased the uptake of I-S1 (this perhaps surprising observation is discussed further below). The evidence for ACE2 involvement in brain I-S1 uptake is weaker than that for lung, as here, uptake was affected by co-injection with soluble ACE2, but not by ACE2 substrates. The finding that I-S1 uptake in the kidney, liver and spleen was unaffected by soluble ACE2 or by ACE2 substrates indicate that receptors other than, or in addition to, ACE2 are involved in uptake of I-S1 in some tissues.

That S1 and even SARS-CoV-2 would use more than one receptor is not surprising when one considers that many viruses use multiple receptors. For example, HIV-1 uses the CD4 and mannose-6-phosphate receptors, and the rabies virus uses the acetylcholine receptor, a nerve growth factor receptor and the neural cell adhesion molecule to enter cells ${ }^{25,36}$. Receptors (besides ACE2) that can bind or are predicted to bind SARS-CoV-2 based on modeling include basigin, cyclophilins, dipeptidyl peptidase- 4 (refs. ${ }^{37,38}$ ) and GRP78 (ref. ${ }^{39}$ ).

One reason that a virus can use such a diversity of receptors is that viruses bind with less specificity than do endogenous receptor ligands. The binding sites for viral proteins are often highly charged regions on the cell-membrane glycoprotein owing to high concentrations of sialic acid, $\mathrm{N}$-acetylglucosamine or heparan sulfate. Coronaviruses in general bind to glycoproteins high in sialic acid ${ }^{40}$. Pioneering work showed that WGA binding to BBB regions rich in sialic acid or $\mathrm{N}$-acetylglucosamine resulted in the transportation of WGA across the BBB through the mechanism of adsorptive transcytosis $^{24}$. WGA coadministered with a weaker inducer of adsorptive transcytosis will often increase rather than block the BBB penetration of the weaker inducer ${ }^{41}$. In the current study, the ability of WGA to increase the I-S1 uptake in brain tissue suggests that $\mathrm{S} 1$ crosses the BBB through adsorptive transcytosis.

Because the spike protein of SARS-CoV-2 is more highly charged than the spike protein of SARS, it has been suggested that it may bind to a larger number of receptors ${ }^{42}$. Some viruses bind receptors rich in heparan sulfate; uptake of those viruses is inhibited by heparin ${ }^{25}$. We showed that I-S1 uptake in liver was inhibited by heparin, but uptake in brain and other peripheral tissues was not. These results show that S1 uses heparan sulfate to bind to liver but not to other tissues. We conclude that a number of receptors are likely involved in S1 uptake; which receptor is most important varies from tissue to tissue. It will be important to identify the membrane-bound glycoproteins that serve as receptors for SARS-CoV-2.

It is unclear why, in our study, co-injection with ACE2 or ACE2 substrates enhanced rather than inhibited uptake of intravenously injected I-S1, but there are some possible explanations. Since S1 does not bind to the ACE2 catalytic site ${ }^{42,43}$, traditional ligand-receptor dose-dependent inhibition kinetics may not occur. The ACE2 we co-injected with I-S1 may have bound circulating Ang II that would normally have competed with I-S1 for binding to membrane-bound ACE2. In addition, $\mathrm{S} 1$ is attached to SARS-CoV-2 as a homotri$\mathrm{mer}^{38}$, but we studied monomeric $\mathrm{S} 1$; it is possible that co-injection of ACE2 ligands altered ACE2 conformation in such a way that it facilitated binding of the S1 monomer.

Risk factors for both contracting COVID-19 and having a poor outcome include male individuals who are positive for the ApoE4 allele in comparison to the $A p o E 3$ allele $^{31-33}$, whereas cytokine storm is a characteristic of severe disease ${ }^{44}$. We found that the influence of sex, ApoE genotype and inflammatory state on I-S1 uptake varied among the tissues. Sex and human ApoE status in mice did not affect uptake of intravenously injected I-S1 in whole brain or lung, but did affect its uptake in olfactory bulb, liver, spleen and kidney, with higher uptake in males. This suggests that some of the risk of poor outcome for males may be related to the degree to which their tissues have an enhanced uptake of S1 or SARS-CoV-2. However, ApoE3, not ApoE4, was associated with higher uptake rates of I-S1 by the olfactory bulb, liver, spleen and kidney, suggesting that the risk associated with ApoE status is unlikely to be due to increased S1 or SARS-CoV-2 tissue uptake.

Inflammation induced by LPS injection increased the amount of intravenously injected I-S1 entering the brain, but this increase was likely due to BBB disruption and not due to enhancement of adsorptive transcytosis; indeed, uptake of I-S1 after correction for $\mathrm{BBB}$ disruption was actually lower in one brain region, the olfactory bulb. LPS-exposed mice had higher I-S1 uptake in lung but lower uptake in spleen and liver; the latter likely explains why these mice had reduced I-S1 clearance from blood. Notably, this decrease in clearance from blood observed in mice in an inflammatory state suggests that all tissues will be exposed to higher S1 levels than in the noninflammatory state.

Fig. 8 | Sex and ApoE genotype influence on I-S1 uptake. a-h, Serum levels and tissue uptake of I-S1 (RayBiotech) and brain uptake of T-Alb following i.v. injection in male and female mice that were homozygous for human APOE3 (E3) or APOE4 (E4). For a, MTRA was performed to calculate the $K_{\mathrm{i}}$ and $V_{\mathrm{i}}$ for T-Alb. In c-h, the $y$ axis shows delta tissue/serum ratios for I-S1, which were corrected for vascular space and nonspecific leakage (Methods). The slopes of the regression lines that result from MTRA measures the rate of influx $\left(K_{\mathrm{i}}\right)$ into the tissues. The $K_{\mathrm{i}}$ values for the four groups (E3 males, E3 females, E4 males and E4 females) were statistically compared by two-way ANOVA with sex and APOE genotype as the independent variables, followed by Tukey's multiple-comparison post hoc tests (a-h). Sex or APOE genotype did not influence changes in brain uptake of T-Alb (a), levels of I-S1 in serum (b) or I-S1 uptake by brain (c) or lung (e) tissue, indicating that these factors do not influence BBB integrity or brain vascular space, clearance from blood or uptake by brain or lung tissue. $\mathbf{d}$. Two-way ANOVA showed a significant effect of sex on I-S1 uptake in the olfactory bulb $(F(1,29)=14.30, P=0.0007)$, accounting for $29 \%$ of the variability. Post hoc Tukey's multiple-comparisons test showed a significantly larger $K_{\mathrm{i}}$ for $E 3$ males compared to E3 females $(P=0.0056)$ and to $\mathrm{E} 4$ females $(P=0.0015)$. APOE genotype had a trend-level effect on uptake in the olfactory bulb $(F(1,29)=3.838, P=0.06)$. $\mathbf{f}$. $A P O E$ genotype had a significant main effect on I-S1 uptake in the liver $(F(1,24)=28.44, P<0.0001)$, accounting for $50 \%$ of the variability, with a lower uptake rate for E4 females compared to $\mathrm{E} 3$ females $(P=0.0057)$ and to $\mathrm{E} 3$ males $(P=0.0001)$, and with a lower uptake rate for $\mathrm{E} 4$ males versus $\mathrm{E} 3$ males $(P=0.0039)$. $\mathbf{g}$, There was a significant main effect of sex on I-S1 uptake in the spleen $(P=0.0004)$, accounting for $20 \%$ of the variability, a main effect of $A p o E$ genotype $(P<0.0001)$, accounting for $43 \%$ of variability, and a significant effect of their interaction $(P=0.0029)$, accounting for $13 \%$ of variability. Multiple comparisons showed faster uptake rates for E3 females compared to E4 females $(P<0.0001)$ to E3 males $(P=0.0003)$ and to E4 males $(P<0.0001)$. h, APOE genotype had a significant effect on I-S1 uptake in the kidney $(P=0.0046)$, accounting for $25 \%$ of variability, with faster uptake in E3 males compared to E4 males $(P=0.0089)$ and to $E 4$ females $(P=0.012)$. The number of mice assigned each group was 11 for $E 3$ females and 10 for the other three groups. However, the number of mice used to calculate the regression lines ranged from 6 to 11 per group, because deviation from linearity was observed that satisfied exclusion criteria (Methods). The $n$ values per group (including the excluded outliers) is shown in Supplementary Table 2. 
A lethal infection can occur after intranasal administration of $\mathrm{SARS}^{35}$. It has been postulated that nasal virus spreads to the lung and from there to blood and brain ${ }^{35}$, but others suggest that SARS-CoV-2 in the nares could spread to the brain through the olfactory nerve ${ }^{45}$, as do many other viruses ${ }^{30}$. Although our findings show that intranasally administered I-S1 can enter mouse brain tissue, they highlight the $\mathrm{BBB}$ as the major route for I-S1 entry into the brain. Moreover, a very small amount $(0.66 \%$ bioavailability after intranasal administration) of I-S1 was found in blood, suggesting poor nasal-to-blood transfer. However, our studies were designed to assess the ability of I-S1 to enter the brain through the olfactory nerve and not to assess its ability to enter the blood via the nasal vasculature. Nevertheless, our results favor some sites other than the nares, such as the lungs, as being the entry point of S1 detected in blood.

It is important to note that although the study shows that I-S1 crosses the BBB in mice, this may not be the case in humans. For that reason, we used in vitro models of the human $\mathrm{BBB}$, which can be useful in studying mechanisms of BBB permeability. The model used in this study is derived from human iPSCs and develops a brain endothelial cell-like phenotype that includes functional BBB influx and efflux transporters and strong barrier properties that permit the study of transport without confounding effects of high baseline leakage ${ }^{46,47}$. In this model, we did not observe significant differences in permeability for I-S1 compared to T-Alb. The apparent absence of I-S1 transport across the BBB in this in vitro model could be due to technical issues, such as blockers of I-S1 binding in the buffers. It could also mean that the iBECs did not express the cell-membrane glycoproteins necessary for I-S1 transport, or that I-S1 is not able to cross the human BBB. A note of caution regarding the validity of using monomeric $\mathrm{S} 1$ as a model for SARS-CoV-2 is that $\mathrm{S} 1$ is normally attached to SARS-CoV-2 as a trimer. However, the S1 protein may be shed from the virus in vivo, and therefore studying S1 monomers may
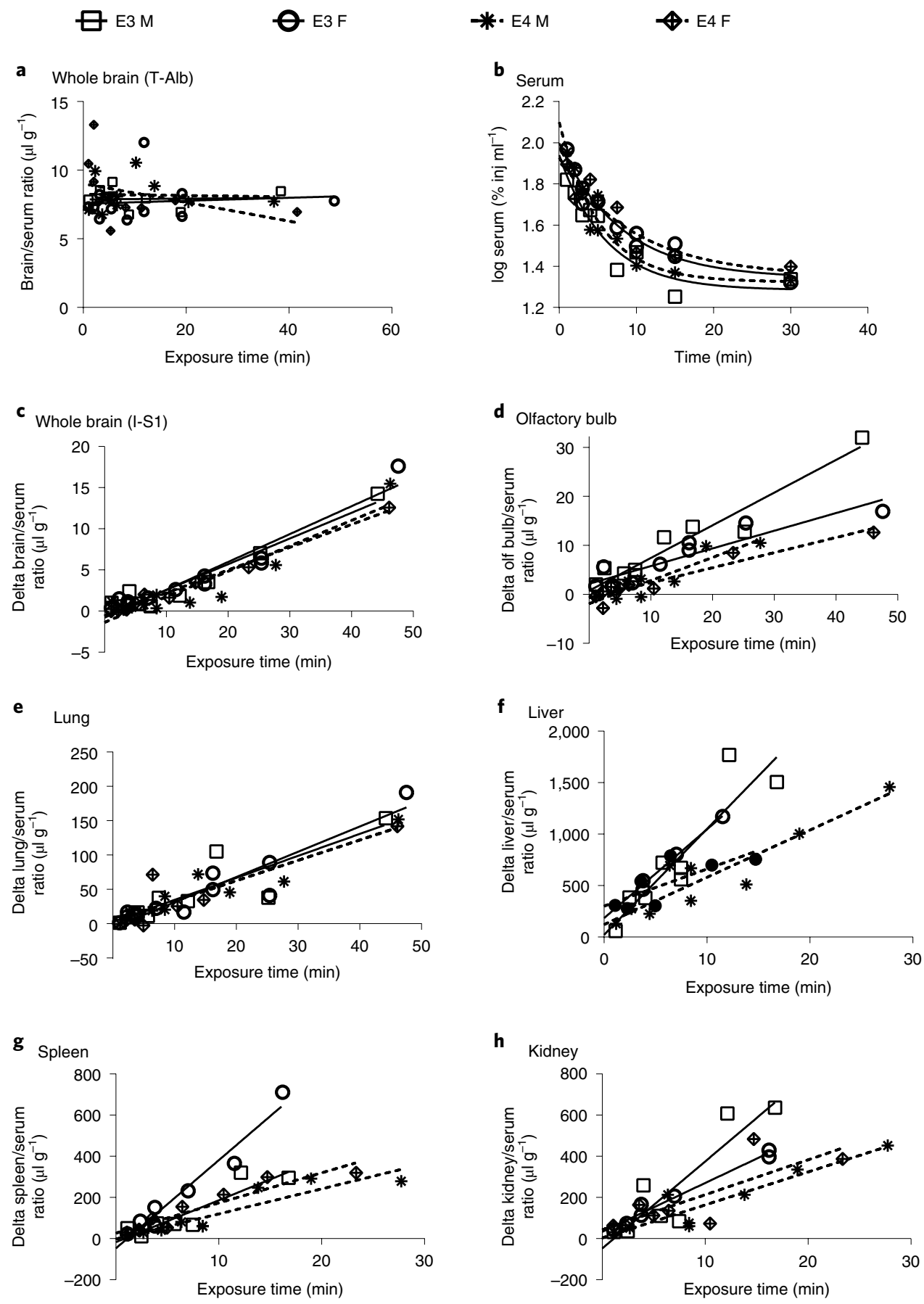
have validity by itself-although there is currently no direct evidence that spike proteins are shed from SARS-CoV-2. Altogether, our results strongly suggest that the $\mathrm{S} 1$ protein can cross the murine BBB through a mechanism resembling adsorptive transcytosis and be taken up by peripheral tissues independently of human ACE2.

\section{Online content}

Any methods, additional references, Nature Research reporting summaries, source data, extended data, supplementary information, acknowledgements, peer review information; details of author contributions and competing interests; and statements of data and code availability are available at https://doi.org/10.1038/ s41593-020-00771-8.

Received: 17 July 2020; Accepted: 30 November 2020;

Published online: 16 December 2020

\section{References}

1. Li, Y. C., Bai, W. Z. \& Hashikawa, T. The neuroinvasive potential of SARS-CoV-2 may play a role in the respiratory failure of COVID-19 patients. J. Med. Virol. 92, 552-555 (2020).

2. Mao, L. et al. Neurologic manifestations of hospitalized patients with coronavirus disease 2019 in Wuhan, China. JAMA Neurol. 77, 1-9 (2020).

3. Saleki, K., Banazadeh, M., Saghazadeh, A. \& Rezaei, N. The involvement of the central nervous system in patients with COVID-19. Rev. Neurosci. 31, 453-456 (2020).

4. Moriguchi, T. et al. A first case of meningitis/encephalitis associated with SARS-Coronavirus-2. Int. J. Infect. Dis. 94, 55-58 (2020).

5. Wang, J., Jiang, M., Chen, X. \& Montaner, L. J. Cytokine storm and leukocyte changes in mild versus severe SARS-CoV-2 infection: review of 3,939 COVID-19 patients in China and emerging pathogenesis and therapy concepts. J. Leukoc. Biol. 108, 17-41 (2020).

6. Bleau, C., Filliol, A., Samson, M. \& Lamontagne, L. Brain invasion by mouse hepatitis virus depends on impairment of tight junctions and beta interferon production in brain microvascular endothelial cells. J. Virol. 89, 9896-9908 (2015)

7. Subbarao, K. et al. Prior infection and passive transfer of neutralizing antibody prevent replication of severe acute respiratory syndrome coronavirus in the respiratory tract of mice. J. Virol. 78, 3572-3577 (2004).

8. $\mathrm{Xu}, \mathrm{J}$. et al. Detection of severe acute respiratory syndrome coronavirus in the brain: potential role of the chemokine mig in pathogenesis. Clin. Infect. Dis. 41, 1089-1096 (2005).

9. Bullen, C. K. et al. Infectability of human BrainSphere neurons suggests neurotropism of SARS-CoV-2. ALTEX 37, 665-671 (2020).

10. Erickson, M. A. \& Banks, W. A. Neuroimmune axes of the blood-brain barriers and blood-brain interfaces: bases for physiological regulation, disease states and pharmacological interventions. Pharmacol. Rev. 70, 278-314 (2018)

11. Oh, S. K. et al. Identification of HIV-1 envelope glycoprotein in the serum of AIDS and ARC patients. J. Acquir. Immune Defic. Syndr. 5, 251-256 (1992).

12. Westendorp, M. O. et al. Sensitization of T cells to CD95-mediated apoptosis by HIV-1 Tat and gp120. Nature 375, 497-500 (1995).

13. Bansal, A. K. et al. Neurotoxicity of HIV-1 proteins gp120 and Tat in the rat striatum. Brain Res. 879, 42-49 (2000).

14. Rychert, J., Strick, D., Bazner, S., Robinson, J. \& Rosenberg, E. Detection of HIV gp120 in plasma during early HIV infection is associated with increased proinflammatory and immunoregulatory cytokines. AIDS Res. Hum. Retroviruses 26, 1139-1145 (2010)

15. Banks, W. A., Kastin, A. J. \& Akerstrom, V. HIV-1 protein gp120 crosses the blood-brain barrier: role of adsorptive endocytosis. Life Sci. 61, L119-L125 (1997)

16. Banks, W. A., Robinson, S. M. \& Nath, A. Permeability of the blood-brain barrier to HIV-1 Tat. Exp. Neurol. 193, 218-227 (2005).

17. Raber, J. et al. Central nervous system expression of HIV-1 Gp120 activates the hypothalamic-pituitary-adrenal axis: evidence for involvement of NMDA receptors and nitric oxide synthase. Virology 226, 362-373 (1996).

18. Banks, W. A. et al. Transport of human immunodeficiency virus type 1 pseudoviruses across the blood-brain barrier: role of envelope proteins and adsorptive endocytosis. J. Virol. 75, 4681-4691 (2001).

19. Banks, W. A., Robinson, S. M., Wolf, K. M., Bess, J. W. Jr. \& Arthur, L. O. Binding, internalization and membrane incorporation of human immunodeficiency virus-1 at the blood-brain barrier is differentially regulated. Neuroscience 128, 143-153 (2004).

20. Weiss, S. R. \& Navas-Martin, S. Coronavirus pathogenesis and the emerging pathogen severe acute respiratory syndrome coronavirus. Microbiol. Mol. Biol. Rev. 69, 635-664 (2005).
21. Yan, R. et al. Structural basis for the recognition of SARS-CoV-2 by full-length human ACE2. Science 367, 1444-1448 (2020).

22. Hoffmann, M. et al. SARS-CoV-2 cell entry depends on ACE2 and TMPRSS2 and is blocked by a clinically proven protease inhibitor. Cell 181, 271-280 (2020).

23. Shang, J. et al. Structural basis of receptor recognition by SARS-CoV-2. Nature 581, 221-224 (2020).

24. Villegas, J. C. \& Broadwell, R. D. Transcytosis of protein through the mammalian cerebral epithelium and endothelium: II. Adsorptive transcytosis of WGA-HRP and the blood-brain and brain-blood barriers. J. Neurocytol. 22, 67-80 (1993).

25. Schweighardt, B. \& Atwood, W. J. Virus receptors in the human central nervous system. J. Neurovirol. 7, 187-195 (2001).

26. Ramos-Kuri, M., Barron Romero, B. L. \& Aguilar-Setien, A. Inhibition of three alphaherpesviruses (herpes simplex 1 and 2 and pseudorabies virus) by heparin, heparan and other sulfated polyelectrolytes. Arch. Med. Res. 27, 43-48 (1996).

27. Nottet, H. S. et al. Mechanisms for the transendothelial migration of HIV-1-infected monocytes into brain. J. Immunol. 156, 1284-1295 (1996).

28. Banks, W. A., Kastin, A. J., Brennan, J. M. \& Vallance, K. L. Adsorptive endocytosis of HIV-1gp120 by blood-brain barrier is enhanced by lipopolysaccharide. Exp. Neurol. 156, 165-171 (1999).

29. Erickson, M. A. \& Banks, W. A. Cytokine and chemokine responses in serum and brain after single and repeated injections of lipopolysaccharide: multliplex quantification with path analysis. Brain Behav. Immun. 25 1637-1648 (2011).

30. van Riel, D., Verdijk, R. \& Kuiken, T. The olfactory nerve: a shortcut for influenza and other viral diseases into the central nervous system. J. Pathol. 235, 277-287 (2015)

31. Kuo, C. L., et al. ApoE e4e4 genotype and mortality with COVID-19 in UK Biobank. J. Gerontol. A Biol. Sci. Med. Sci. 75, 1801-1803 (2020).

32. Gebhard, C., Regitz-Zagrosek, V., Neuhauser, H. K., Morgan, R. \& Klein, S. L. Impact of sex and gender on COVID-19 outcomes in Europe. Biol. Sex. Differ. 11, 29 (2020).

33. Li, L. Q. et al. COVID-19 patients' clinical characteristics, discharge rate and fatality rate of meta-analysis. J. Med. Virol. 92, 577-583 (2020)

34. Walls, A. C. et al. Tectonic conformational changes of a coronavirus spike glycoprotein promote membrane fusion. Proc. Natl Acad. Sci. USA 114 11157-11162 (2017).

35. McCray, P. B. Jr. et al. Lethal infection of K18-hACE2 mice infected with severe acute respiratory syndrome coronavirus. J. Virol. 81, 813-821 (2007)

36. Dohgu, S., Ryerse, J. S., Robinson, S. M. \& Banks, W. A. Human immunodeficiency virus-1 uses the mannose-6-phosphate receptor to cross the blood-brain barrier. PLoS ONE 7, e39565 (2012).

37. Radzikowska, U. et al. Distribution of ACE2, CD147, CD26 and other SARS-CoV-2-associated molecules in tissues and immune cells in health and in asthma, COPD, obesity, hypertension and COVID-19 risk factors. Allergy 75, 2829-2845 (2020)

38. Vankadari, N. \& Wilce, J. A. Emerging WuHan (COVID-19) coronavirus: glycan shield and structure prediction of spike glycoprotein and its interaction with human CD26. Emerg. Microbes Infect. 9, 601-604 (2020).

39. Ibrahim, I. M., Abdelmalek, D. H., Elshahat, M. E. \& Elfiky, A. A. COVID-19 spike-host cell receptor GRP78 binding site prediction. J. Infect. 80, 554-562 (2020).

40. Guruprasad, L. Human coronavirus spike protein-host receptor recognition. Prog. Biophys. Mol. Biol. https://doi.org/10.1016/j.pbiomolbio.2020.10.006 (2020).

41. Banks, W. A. \& Kastin, A. J. Characterization of lectin-mediated brain uptake of HIV-1 gp120. J. Neurosci. Res. 54, 522-529 (1998).

42. Hassanzadeh, K., et al. Considerations around the SARS-CoV-2 spike protein with particular attention to COVID-19 brain infection and neurological symptoms. ACS Chem. Neurosci. https://doi.org/10.1021/ acschemneuro.0c00373 (2020).

43. Prabakaran, P., Xiao, X. \& Dimitrov, D. S. A model of the ACE2 structure and function as a SARS-CoV receptor. Biochem. Biophys. Res. Commun. 314, 235-241 (2004)

44. Li, X. et al. Risk factors for severity and mortality in adult COVID-19 inpatients in Wuhan. J. Allergy Clin. Immunol. 146, 110-118 (2020)

45. Machado, C., DeFina, P. A., Chinchilla, M., Machado, Y. \& Machado, Y. Brainstem dysfunction in SARS-COV-2 infection can be a potential cause of respiratory distress. Neurol. India 68, 989-993 (2020).

46. Al-Ahmad, A. J. Comparative study of expression and activity of glucose transporters between stem cell-derived brain microvascular endothelial cells and hCMEC/D3 cells. Am. J. Physiol. Cell Physiol. 313, C421-c429 (2017)

47. Lippmann, E. S. et al. Derivation of blood-brain barrier endothelial cells from human pluripotent stem cells. Nat. Biotechnol. 30, 783-791 (2012).

Publisher's note Springer Nature remains neutral with regard to jurisdictional claims in published maps and institutional affiliations.

(c) The Author(s), under exclusive licence to Springer Nature America, Inc. 2020 


\section{Methods}

Mice. All mouse studies were approved by the local Institutional Animal Care and Use Committee at Oregon Health \& Sciences University and the Veterans Affairs Puget Sound Health Care System (VAPSHCS) and conducted in facilities approved by the American Association for Accreditation of Laboratory Animal Care (AAALAC). Male CD-1 mice (6-10 weeks old) were purchased from Charles River Laboratories (Hollister). A total of 204 CD-1 males were used for all studies. Human E3- and E4-targeted replacement (TR) male and female mice, generated as described previously ${ }^{48}$, were bred at the Oregon Health \& Sciences University before transfer to the VAPSHCS for the experiments. E3 and E4 TR mice were approximately 4 months of age on the day of the study. A total of 21 E3 and 20 E4 TR mice were used for all studies. Mice had ad libitum access to food and water and were kept on a 12/12-h light/dark cycle. The temperature was maintained at $18-23^{\circ} \mathrm{C}$ and humidity was maintained at $40-60 \%$. For all experiments, mice were anesthetized with an intraperitoneal binjection of $0.15-0.2 \mathrm{ml}$ of $40 \%$ urethane to minimize pain and distress. Anesthetized mice were placed on a heating pad until time of use. At the end of each study, mice were euthanized by decapitation while under anesthesia.

Sources and radioactive labeling of proteins. The $\mathrm{S} 1$ proteins were provided by the manufacturers (RayBiotech, 230-30161, Val 16-Gln 690; AMSBIO, AMS. S1N-C52H3, Val 16-Arg 685). The proteins were dissolved in PBS (pH 7.4) at a concentration of $0.45-0.61 \mathrm{mg} \mathrm{ml}^{-1}$. The proteins were produced in HEK293 cell lines, had C-terminal His tags, were calculated to be about $76 \mathrm{kDa}$ in protein, but migrated on gel at $100-120 \mathrm{kDa}$ because of glycosylation. Upon receipt, the $S 1$ proteins were thawed and aliquoted into $5-\mu$ g portions, and either used immediately or stored at $-80^{\circ} \mathrm{C}$ until use. The $5 \mu \mathrm{g}$ of thawed $\mathrm{S} 1$ protein was radioactively labeled with $1 \mathrm{mCi}{ }^{125} \mathrm{I}$ (Perkin Elmer) using the chloramine- $\mathrm{T}$ method, as described previously ${ }^{49}$. The I-S1 was purified on a column of G-10 Sephadex (GE Healthcare) and eluted with PBS into glass tubes containing 1\% BSA in lactated Ringer's solution (BSA-LR). We estimated based on the amount of protein iodinated that the specific activity of I-S1 was approximately $11 \mathrm{Ci}$ $\mathrm{g}^{-1}$ or about $12.5 \mathrm{ng}$ per 300,000 c.p.m. BSA (Sigma) was labeled with ${ }^{99 \mathrm{~m}} \mathrm{Tc}$ (GE Healthcare) using the stannous tartrate method ${ }^{50}$. T-Alb was purified on a column of G-10 Sephadex. Both of the I-S1's and the T-Alb were more than $90 \%$ acid precipitable. The molecular weight of the labeled proteins was confirmed by running 200,000-600,000 c.p.m. activity in 1× LDS buffer (Invitrogen) with or without reducing agent (Invitrogen) on a $4-12 \%$ Bis-Tris gel (GenScript) in MOPS buffer (Invitrogen). The gel was then fixed for $30 \mathrm{~min}$ in $10 \%$ acetic acid $/ 50 \%$ methanol, washed $3 \times$ with water and then dried using a DryEase Mini-Gel Drying System (Invitrogen). Dried gels were exposed on autoradiography film for $24 \mathrm{~h}$ and then developed. Major bands of I-S1 from RayBiotech and AMSBIO migrated at their predicted molecular weight patterns, based on the manufacturer's data (Extended Data Fig. 1).

Measurement of blood-to-brain entry rate. MTRA ${ }^{51,52}$ was used to measure the unidirectional blood-to-brain influx constant $\left(K_{\mathrm{i}}\right)$ for I-S1. In anesthetized mice, the left jugular vein was exposed for an i.v. injection of $0.1 \mathrm{ml}$ BSA-LR containing $3 \times 10^{5}$ c.p.m of I-S1. T-Alb $\left(6 \times 10^{5}\right.$ c.p.m. $)$ was also included in the injection for measurement of the vascular space for the brain and the albumin space for peripheral tissues. At time points between 1 and $30 \mathrm{~min}$, blood was collected from the carotid artery. Blood was centrifuged at $3,200 \mathrm{~g}$ for $10 \mathrm{~min}$ and $50 \mu \mathrm{l}$ of serum was collected. The whole brain, kidney and spleen and portions of the lung and liver were removed and weighed. Tissues and serum were placed into a Wizard ${ }^{2}$ gamma counter (Perkin Elmer), and the levels of radioactivity were measured. Results for brain and other tissues were expressed as the tissue/serum ratio in units of $\mu \mathrm{g}^{-1}$ for both I-S1 and T-Alb. For each individual tissue, its tissue/serum ratio for T-Alb was subtracted from its tissue/serum ratio for I-S1, yielding a 'delta' value. These delta values were thus corrected for vascular space and any nonspecific leakage into tissue and so represent I-S1 protein uptake that was not due to trapping in the vascular space or to leakage. The delta brain/serum ratios were plotted against exposure time, a calculation that corrects for clearance from blood:

$$
\text { Expt }=\left[\int_{0}^{t} \mathrm{Cp}(\tau) \mathrm{d} \tau\right] / \mathrm{Cpt}
$$

where $t$ is the time between the i.v. injection and sampling, Cp is the c.p.m. per $\mathrm{ml}$ of arterial serum, Cpt is the c.p.m. per $\mathrm{ml}$ of arterial serum at time $t$, and $\tau$ is the dummy variable for time. The slope of the linear portion of the relation of tissue/ serum ratio versus exposure time measures the unidirectional influx rate $\left(K_{\mathrm{i}}\right.$ in $\mu \mathrm{l}$ $\left.\mathrm{g}^{-1} \mathrm{~min}^{-1}\right)$ and the $y$ intercept measures $V_{\mathrm{i}}$, the vascular space and initial luminal binding at $t=0$ (refs. ${ }^{51,52}$ ):

$$
\text { Tissue } / \text { serum ratio }=K_{i}(\operatorname{expt})+V_{i}
$$

Calculations of area under the curve and percentage of injected doses. The AUC for the level of radioactivity in blood from 0-30 min was calculated using Prism 8.0 software (GraphPad). Results for serum were expressed as the percentage of the injected dose per $\mathrm{ml}$ of blood $\left(\%\right.$ inj $\left.\mathrm{ml}^{-1}\right)$. The percentage of the injected dose per gram of brain ( $\%$ inj $\mathrm{g}^{-1}$ ) was calculated by multiplying the delta brain/serum value by the percentage of injected dose per $\mathrm{ml}$ for I-S1.

Stability of I-S1 in brain and blood. Anesthetized mice received an injection into the jugular vein of $0.1 \mathrm{ml}$ of BSA-LR containing $6 \times 10^{5}$ c.p.m. of I-S1 and $6 \times 10^{5}$ c.p.m. of T-Alb. Ten minutes after the injection, arterial blood was collected from the abdominal aorta, the thorax opened and the descending thoracic artery clamped, both jugular veins severed and $20 \mathrm{ml}$ of lactated Ringer's solution perfused through the left ventricle of the heart to wash out the vascular space of the brain. The whole brain was then removed. Whole blood was centrifuged and $10 \mu \mathrm{l}$ of serum was added to $500 \mu \mathrm{l}$ of BSA-LR and combined with an equal part of $30 \%$ trichloroacetic acid, mixed, centrifuged and the supernatant and pellet counted. Whole brains were homogenized in BSA-LR with complete mini protease inhibitor (Roche; one tablet per $10 \mathrm{ml}$ buffer) with a handheld glass homogenizer and centrifuged. The resulting supernatant was combined with equal parts of $30 \%$ trichloroacetic acid, mixed, centrifuged and the supernatant and pellet counted. To determine the amount of degradation of I-S1 or T-Alb that occurred during processing, I-S1 and T-Alb were added to brains and arterial whole blood from animals that had not been injected with radioactivity and processed immediately as above. The percentage of radioactivity that was precipitated by acid $(\% \mathrm{P})$ in all of these samples was calculated by the equation:

$$
\% P=100(S) /(S+P)
$$

where $S$ is the c.p.m. in the supernatant and $P$ is the c.p.m. in the pellet.

Capillary depletion of brain. The capillary depletion method as adapted to mice was used to separate cerebral capillaries and vascular components from brain parenchyma ${ }^{53,54}$. We used the variant of the technique that also estimates reversible binding to the capillary lumen. The latter is done by assessing two groups of mice: one with a vascular washout step, which removes material reversibly bound to the capillary lumen (washout group), and one without the washout step (non-washout group). The difference between these groups represents material that was reversibly adhering to the capillary lumen (equation 4). Mice were anesthetized and received an i.v. injection of $6 \times 10^{5}$ c.p.m. T-Alb with $6 \times 10^{5}$ c.p.m. I-S1 in $0.1 \mathrm{ml}$ BSA-LR. At 5, 10 and $30 \mathrm{~min}$ later, blood was obtained from the carotid artery, and the brain (non-washout group) was extracted. In a separate group of mice, blood was taken from the abdominal aorta at 5,10 and $30 \mathrm{~min}$, the thorax was opened and the descending thoracic artery clamped, both jugulars severed, and $20 \mathrm{ml}$ of lactated Ringer's solution infused via the left ventricle of the heart to wash out the vascular contents of the brain and remove any material reversibly associated with the capillary lumen (washout group). Each whole brain was homogenized in glass with physiological buffer (10 mM HEPES, $141 \mathrm{mM} \mathrm{NaCl}, 4 \mathrm{mM} \mathrm{KCl}, 2.8 \mathrm{mM}$ $\mathrm{CaCl}_{2}, 1 \mathrm{mM} \mathrm{MgSO}_{4}, 1 \mathrm{mM} \mathrm{NaH} \mathrm{PO}_{4}-\mathrm{H}_{2} \mathrm{O}, 10 \mathrm{mM}$ D-glucose (pH 7.4)) and mixed thoroughly with $26 \%$ dextran. The homogenate was centrifuged at $4,255 \mathrm{~g}$ for $15 \mathrm{~min}$ at $4^{\circ} \mathrm{C}$. The pellet, containing the capillaries, and the supernatant, representing the brain parenchymal space, were carefully separated. Radioactivity levels in the capillary pellet, the brain supernatant and the arterial serum were determined for both T-Alb and I-S1 and expressed as the capillary/serum and brain parenchyma/serum ratios. The I-S1 parenchymal ratios were corrected for vascular contamination by subtracting the corresponding ratios for T-Alb; these results are reported as the delta brain parenchyma/serum ratios. The amount of $\mathrm{S} 1$ in the brain parenchymal space was taken as the delta brain parenchymal space from the washout group $\left(P_{\mathrm{W}}\right)$, the amount in the capillary as the capillary from the washout group $\left(C_{\mathrm{W}}\right)$, and the amount of material loosely binding to the luminal surface (luminal) as:

$$
\text { Luminal }=(P+C)-\left(P_{W}+C_{W}\right)
$$

Where $P$ is the delta brain parenchymal space and $C$ is the capillary space, both from the non-washout groups.

Effects of wheatgerm agglutinin and heparin. We co-injected WGA with I-S1 to determine the role of glycoproteins containing sialic acid and $\mathrm{N}$-acetylglucosamine in the uptake of S1 by the BBB and other tissues. Mice were anesthetized, after which the jugular vein and right carotid artery were exposed. Mice then received a jugular vein injection of $0.1 \mathrm{ml}$ of BSA-LR containing $3 \times 10^{5}$ c.p.m. of I-S1 and $6 \times 10^{5}$ c.p.m. of T-Alb and, in a subset of mice, $10 \mu \mathrm{g}$ of the plant lectin WGA (Sigma). Brain, tissues and serum samples were collected 5 min later and tissue/ serum ratios calculated as above in units of $\mu$ l per gram. Heparan sulfate is used as a receptor by some viruse ${ }^{25}$ and heparin by binding to viral proteins can block viral entry into brain ${ }^{19,26}$. Therefore, separate groups of mice had heparin (12 U per mouse) included in the injection.

Saturation of I-S1 and binding to ACE2 enzyme. In anesthetized mice, the left jugular vein was exposed for an i.v. injection of $0.1 \mathrm{ml}$ BSA-LR containing $3 \times 10^{5}$ c.p.m. of I-S1 (RayBiotech) and $6 \times 10^{5}$ c.p.m. of T-Alb. For some mice, the injection contained $1 \mu \mathrm{g}$ per mouse of unlabeled S1 (AMSBIO), mouse acyl ghrelin (CBio), angiotensin II (Tocris) or human ACE2 (R\&D). Ten minutes after i.v. 
injection, whole blood was obtained from the carotid artery and centrifuged after clotting. The whole brain, olfactory bulb, kidney, spleen and portions of the liver and lung were removed. The levels of radioactivity in the arterial serum and the tissues were determined and the results expressed as the percentage of the injected I-S1 per $\mathrm{ml}$ for serum and delta tissue/serum ratios for the tissues.

Lipopolysaccharide injections. Male CD-1 mice aged 6-10 weeks were given an intraperitoneal injection of $3 \mathrm{mg} \mathrm{kg}^{-1}$ LPS from S. typhimurium (Sigma) dissolved in sterile normal saline at 0,6 and $24 \mathrm{~h}$. At $28 \mathrm{~h}$, mice were anesthetized and the left jugular vein and right carotid artery exposed. The mice were given an i.v. injection of $6 \times 10^{5}$ c.p.m. of I-S1 and $6 \times 10^{5}$ c.p.m. of T-Alb in $0.1 \mathrm{ml}$ of BSA-LR into the left jugular vein. Arterial blood was collected from the right carotid artery 10 min later, the mouse immediately decapitated, the brain removed, dissected into regions (olfactory bulb, frontal cortex, occipital cortex, parietal cortex, thalamus, hypothalamus, striatum, hippocampus, pons-medulla, cerebellum and midbrain) and the regions weighed. Kidney, spleen and portions of the liver and lung were also removed and weighed. Serum was obtained by centrifuging the carotid artery blood for $10 \mathrm{~min}$ at $4,255 \mathrm{~g}$. Levels of radioactivity in serum, brain regions, and tissues were measured in a gamma counter. Whole-brain values were calculated by summing levels of radioactivity and weight for all brain regions except for the olfactory bulb. Data for brain regions from control mice (not receiving LPS) were separately analyzed for differences among brain regions and also used in comparisons with LPS-treated mice. The levels of radioactivity in the arterial serum and the brain regions and tissues were determined and the results expressed as the percentage of the injected I-S1 per $\mathrm{ml}$ for serum and delta tissue/serum ratios $\left(\mu \mathrm{g} \mathrm{g}^{-1}\right)$ for the tissues.

Intranasal delivery of I-S1. Anesthetized mice were placed in the supine position and received a $1-\mu \mathrm{l}$ injection of $2 \times 10^{5}-3 \times 10^{5}$ c.p.m. I-S1 in BSA-LR administered into each naris, delivered to the level of the cribriform plate ( $4 \mathrm{~mm}$ in depth), using a 10- $\mu$ l MultiFlex tip (Thermo Fisher Scientific). After administration, the mouse remained in the supine position for $30 \mathrm{~s}$ before being placed on the left side. Arterial blood was collected from the right carotid artery 10 or $30 \mathrm{~min}$ later, the mouse immediately decapitated, the brain removed and dissected into regions (olfactory bulb, frontal cortex, occipital cortex, parietal cortex, thalamus, hypothalamus, striatum, hippocampus, pons-medulla, cerebellum and midbrain) and the regions weighed. Serum was obtained by centrifuging the carotid artery blood for $10 \mathrm{~min}$ at $4,255 \mathrm{~g}$. Levels of radioactivity in serum and brain regions were measured in a Wizard ${ }^{2}$ gamma counter. Whole-brain values were calculated by summing levels of radioactivity and weight for all brain regions except for the olfactory bulb. The levels of radioactivity in the arterial serum and the tissues were determined and the results expressed as the percentage of injected I-S1 per $\mathrm{ml}$ for serum and the percentage of injected I-S1 per gram of brain region calculated.

MTRA in ApoE mice. Human APOE TR mice expressing human ApoE3 or ApoE4, under control of the mouse $A p o E$ promoter and on the C57BL/6J background, were provided by P. Sullivan for breeding ${ }^{55,56}$, as described previously ${ }^{57}$. With TR, the resulting gene contains the mouse $A p o E$ promoter with the mouse $A p o E$ being replaced by the human $A p o E$ so that only the human gene, and not the mouse gene, is expressed. The colony is maintained by homozygous breeding. To prevent genetic drift, regularly, the human $A p o E$ mice expressing different isoforms are crossed with each other and subsequently again bred to homozygosity to refresh the colony. Male and female mice that were homozygous for either ApoE3 or ApoE4 were studied by MTRA as described above. Two-way ANOVA used sex and APOE genotype as independent variables. As described above, T-Alb tissue/serum ratios were used to measure and correct for any BBB disruption.

Transport of I-S1 across iPSC-derived brain endothelial-like cells. The iBECs were derived from the GM25256 iPSC line (Coriell Institute) using the method by Neal et $a .^{58}$ with a seeding density of 15,000 cells per well for differentiation, which was found to be optimal for this cell line. Use of this stem cell line was in accordance with a Material Transfer Agreement between the VAPSHCS and the Coriell Institute and was approved by the VAPSHCS Institutional Biosafety Committee. Briefly, iPSCs were grown to optimal density on plates coated with Matrigel (VWR, 62405-134) in E8 Flex medium (Thermo Fisher Scientific, A2858501), and then passaged using Accutase (Thermo Fisher Scientific, A1110501) onto Matrigel-coated plates in E8 Flex medium plus $10 \mu \mathrm{M}$ ROCK inhibitor Y-27632 (R\&D Systems, 1254). The next day, the medium was changed to E6 (Thermo Fisher Scientific, A1516401), and E6 changes continued daily for three more days. Next, the medium was changed to human endothelial serum-free medium (HESFM; Thermo Fisher Scientific, 11111044) supplemented with $20 \mathrm{ng} \mathrm{ml}^{-1}$ of basic fibroblast growth factor (bFGF; Peprotech, 100-18B), $10 \mu \mathrm{M}$ retinoic acid (Sigma, R2625) and 1\% B27 supplement (Thermo Fisher Scientific, 17504044). At $48 \mathrm{~h}$ later, iBECs were subcultured onto 24-well Transwell inserts (Corning, 3470) coated with $1 \mathrm{mg} \mathrm{m}^{-1}$ collagen IV (Sigma, C5533) and $5 \mathrm{mM}$ fibronectin (Sigma $\mathrm{F} 1141$ ) in HESFM $+20 \mathrm{ng} \mathrm{ml}^{-1} \mathrm{bFGF}, 10 \mathrm{uM}$ retinoic acid and $1 \% \mathrm{~B} 27$. At $24 \mathrm{~h}$ after subculture, the medium was changed to HESFM + 1\% B27 without bFGF or retinoic acid, and transendothelial electrical resistance (TEER) was recorded using an End EVOM2 Voltohmmeter (World Precision Instruments) coupled to an EndOhm cup chamber. TEER measurements occurred daily and S1 transport experiments were conducted when TEER stabilized, between 10-13 d in vitro. TEER values in these studies exceeded $1,000 \Omega \mathrm{cm}^{2}$, and TEER mean values were confirmed to be equal among groups just before starting the transport study.

Before transport studies, the medium was changed and cells were equilibrated in the incubator for $20 \mathrm{~min}$. Warm HESFM + 1\% B27, 1 million c.p.m. of T-Alb and 500,000 c.p.m. of I-S1 were then added in a volume of $100 \mu \mathrm{l}$ to the luminal chamber. After incubation times of $10,20,30$ and $45 \mathrm{~min}$ at $37^{\circ} \mathrm{C}, 500-\mu \mathrm{l}$ volumes of medium from the abluminal chamber were collected and replaced with fresh prewarmed medium. Samples were then acid precipitated by adding a final concentration of $1 \%$ BSA to visualize the pellet and 15\% trichloroacetic acid to precipitate the proteins in solution. The samples were centrifuged at $4,255 \mathrm{~g}$ for $15 \mathrm{~min}$ at $4{ }^{\circ} \mathrm{C}$. Radioactivity in the pellet was counted in the gamma counter and the permeability surface-area coefficients for T-Alb and I-S1 were calculated according to the method by Dehouck et al. ${ }^{59}$. Clearance was expressed as $\mu \mathrm{l}$ of radioactive tracer that was transported from the luminal to abluminal chamber, calculated from the initial level of acid-precipitable radioactivity added to the luminal chamber and the final level of radioactivity in the abluminal chamber:

$$
\text { Clearance }(\mu \mathrm{l})=[\mathrm{C}]_{\mathrm{C}} \times \mathrm{VC} /[\mathrm{C}]_{\mathrm{L}}
$$

Where $[C]_{L}$ is the initial concentration of radioactivity in the luminal chamber (in c.p.m. $\left.\mu \mathrm{l}^{-1}\right),[C]_{\mathrm{C}}$ is the concentration of radioactivity in the abluminal chamber (c.p.m. $\mu \mathrm{l}^{-1}$ ) and $V_{\mathrm{c}}$ is the volume of the abluminal chamber in $\mu \mathrm{l}$. The volume cleared was plotted versus time, and the slope was estimated by linear regression. The slopes of clearance curves for the iBEC monolayer plus Transwell membrane was denoted by PS $_{\text {app, }}$, where PS is the permeability $\times$ surface-area product (in

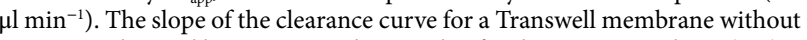

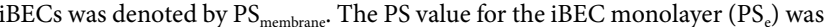
calculated from $1 / \mathrm{PS}_{\text {app }}=1 / \mathrm{PS}_{\text {membrane }}+1 / \mathrm{PS}_{\mathrm{e}}$. The $\mathrm{PS}_{\mathrm{e}}$ values were divided by the surface area of the Transwell inserts $\left(0.33 \mathrm{~cm}^{2}\right)$ to generate the endothelial permeability coefficient $\left(P_{\mathrm{e}}\right.$; in $\left.\mu \mathrm{l} \mathrm{min}^{-1} \mathrm{~cm}^{2}\right)$.

Statistics and reproducibility. Sample size, randomization and blinding. Sample sizes were predetermined based on the variance that is known from previously conducting similar experiments on BBB transport. We selected samples sizes to provide a power of $0.8-0.9$ based on $30-40 \%$ differences between means. Anesthetized mice were randomized between test groups by alternating their assignments. Transwells were assessed for TEER before experiments and assigned to groups in such a way that TEER values between groups had approximately equal means and variances. Blinding was not done for experiments or analyses because this knowledge was required to carry out experiments and analysis.

Data exclusion and replication. For MTRA, the method calls for exclusion of data points that contribute to nonlinearity of the curve. Outliers whose exclusion improved the $r^{2} \geq 0.2$ were excluded from the analysis (excluded points are denoted by filled circles in Figs. 2 and 3 and further explained in the legends). For ANOVAs and comparisons of means, the Grubbs outlier exclusion test (alpha $<0.05$ ) was applied once to detect single outliers, and any outliers that were excluded by this method were stated in the figure legends and their values provided. Each figure was generated as a single experimental replicate, with the exception of iPSC studies where $\mathrm{S} 1$ and albumin transport were compared in three independent experiments. However, use of T-Alb as an internal control for all experiments allowed us to track consistency between experiments with different designs based on its predictable tissue/serum ratios. Further, the I-S1 tissue/serum ratios taken at the same time points from different experiments could be compared, and agreed well with each other, demonstrating a reproducible observation of I-S1 transport into the brain and other tissues.

Statistical analysis. Prism 8.0 was used for all statistical calculations (GraphPad). Simple linear regression analysis was used to calculate slopes and intercepts, and the error terms for the slope and $y$ intercept are the standard errors. As required by MTRA, only the linear portion of the slope was used to calculate $K_{\mathrm{i}}$. ANCOVA was used to determine whether slopes and intercepts of two lines differed, and two-way ANOVA was used to determine effects of sex and genotype on regression lines in the APOE mouse studies. Two-tailed $t$-tests were used to compare two means, and a one-way or two-way ANOVA and multiple-comparisons testing were used when more than two means were compared. The statistical tests used are specified in all figure legends. Data distribution was assumed to be normal, but this was not formally tested. However, all data points are shown with the mean and standard deviation.

Reporting Summary. Further information on research design is available in the Nature Research Reporting Summary linked to this article.

\section{Data availability}

The data that support the findings of this study are available from the corresponding author upon reasonable request. Source data are provided with this paper. 


\section{References}

48. Rodriguez, G. A., Burns, M. P., Weeber, E. J. \& Rebeck, G. W. Young APOE4 targeted replacement mice exhibit poor spatial learning and memory, with reduced dendritic spine density in the medial entorhinal cortex. Learn Mem. 20, 256-266 (2013).

49. Montelaro, R. C. \& Rueckert, R. R. On the use of chloramine-T to iodinate specifically the surface proteins of intact enveloped viruses. J. Gen. Virol. 29, 127-131 (1975).

50. Wang, Y. F., Chuang, M. H., Chiu, J. S., Cham, T. M. \& Chung, M. I. On-site preparation of technetium-99m-labeled human serum albumin for clinical application. Tohoku J. Exp. Med. 211, 379-385 (2007).

51. Blasberg, R. G., Fenstermacher, J. D. \& Patlak, C. S. Transport of alpha-aminoisobutyric acid across brain capillary and cellular membranes. J. Cereb. Blood Flow Metab. 3, 8-32 (1983).

52. Blasberg, R. G., Patlak, C. S. \& Fenstermacher, J. D. Selection of experimental conditions for the accurate determination of blood-brain transfer constants from single-time experiments: a theoretical analysis. J. Cereb. Blood Flow Metab. 3, 215-225 (1983).

53. Triguero, D., Buciak, J. \& Pardridge, W. M. Capillary depletion method for quantification of blood-brain barrier transport of circulating peptides and plasma proteins. J. Neurochem. 54, 1882-1888 (1990).

54. Gutierrez, E. G., Banks, W. A. \& Kastin, A. J. Murine tumor necrosis factor alpha is transported from blood to brain in the mouse. J. Neuroimmunol. 47, 169-176 (1993).

55. Knouff, C. et al. ApoE structure determines VLDL clearance and atherosclerosis risk in mice. J. Clin. Invest. 103, 1579-1586 (1999).

56. Sullivan, P. M. et al. Targeted replacement of the mouse apolipoprotein E gene with the common human APOE3 allele enhances diet-induced hypercholesterolemia and atherosclerosis. J. Biol. Chem. 272, 17972-17980 (1997).

57. Siegel, J. A., Haley, G. E. \& Raber, J. Apolipoprotein E isoform-dependent effects on anxiety and cognition in female TR mice. Neurobiol. Aging 33, 345-358 (2012).

58. Neal, E. H. et al. A simplified, fully defined differentiation scheme for producing blood-brain barrier endothelial cells from human iPSCs. Stem Cell Rep. 12, 1380-1388 (2019).
59. Dehouck, M. P. et al. Drug transfer across the blood-brain barrier: correlation between in vitro and in vivo models. J. Neurochem. 58, 1790-1797 (1992).

\section{Acknowledgements}

This work was supported by the VAPSHCS (W.A.B. and M.A.E.) and research grant awards from the National Institutes of Health (R21 AG065928-01 to M.A.E. and RF-1 AG059088 to W.A.B. and J.R.). We thank R. Weaver, S. Pemberton and D. Quaranta for technical assistance.

\section{Author contributions}

E.M.R.: experimental design, experimental work and data analysis (mouse experiments), writing, editing and graphics. A.F.L.: writing, editing, experimental work and data analysis (mouse experiments). K.M.H.: writing, editing, experimental work and data analysis (protein labeling and characterization and mouse experiments). L.M.W.: experimental work and data analysis (in vitro studies), writing and editing. M.J.R.: experimental work (mouse experiments), experimental design, writing and editing. K.K.B.: experimental work (mouse experiments), writing and editing. S.J.H.: experimental work ( $A P O E$ mouse husbandry), writing and editing. J.R.: writing, editing and experimental design. W.A.B.: experimental design, statistics, writing, editing and graphics. M.A.E.: writing, editing, experimental design and experimental work (protein labeling, mouse experiments and in vitro studies).

\section{Competing interests}

The authors declare no competing interests.

\section{Additional information}

Extended data is available for this paper at https://doi.org/10.1038/s41593-020-00771-8. Supplementary information is available for this paper at https://doi.org/10.1038/ s41593-020-00771-8.

Correspondence and requests for materials should be addressed to W.A.B.

Reprints and permissions information is available at www.nature.com/reprints.

Peer review Information Nature Neuroscience thanks Jean Millet and the other, anonymous, reviewer(s) for their contribution to the peer review of this work. 


\section{RayBiotech}

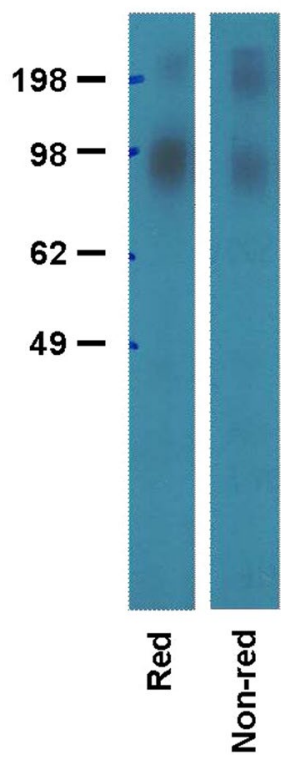

AMSBIO

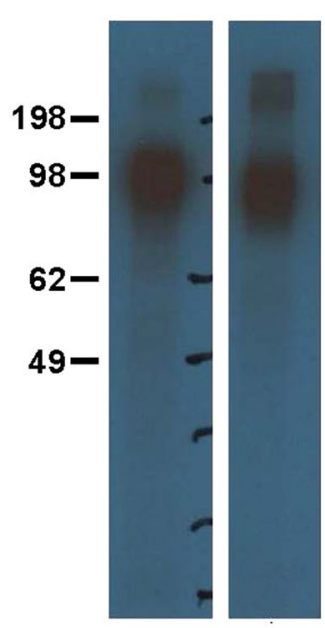

$\begin{array}{ll}\text { 윰 } & \text { 몬 } \\ & \text { 을 }\end{array}$

Extended Data Fig. 1 | Gel Autoradiography of I-S1 from RayBiotech and AMSBIO. Cropped images of Fraction 9 of I-S1 from RayBiotech (left panel, 1ul of approximately 300,000 CPM run under reducing and non-reducing conditions, exposed to film for 24 hours), and from AMSBIO (right panel, 1 ul of approximately 600,000 CPM run under reducing and non-reducing conditions. In each case, both the reduced and non-reduced gels migrated at the molecular weights predicted by the manufacturers. The autoradiography gels to validate size were run once. The quality of subsequent I-S1 labeling was confirmed by acid precipitation, described in methods. 


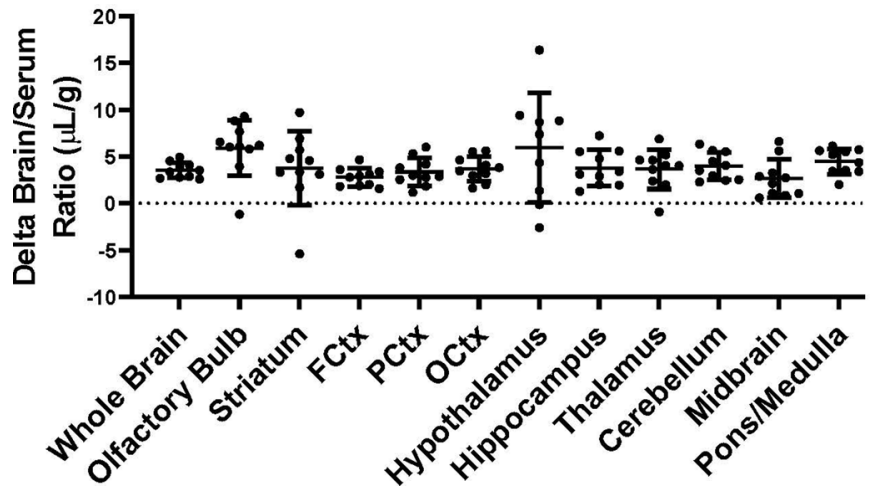

Extended Data Fig. 2 | I-S1 is uniformly taken up by all brain regions. Mice were given an injection of I-S1 (RayBiotech) and olfactory bulb, whole brain, and blood were collected $10 \mathrm{~min}$ later. Brains were dissected into the 10 regions shown. One-way ANOVA with brain regions as the independent variable showed a trend for differences $(p=0.09)$ and post-hoc multiple comparisons tests showed no differences among the brain regions. $\mathrm{N}=11 \mathrm{mice}$. FCtx $=$ frontal cortex, PCtx = parietal cortex, OCtx = occipital cortex. 


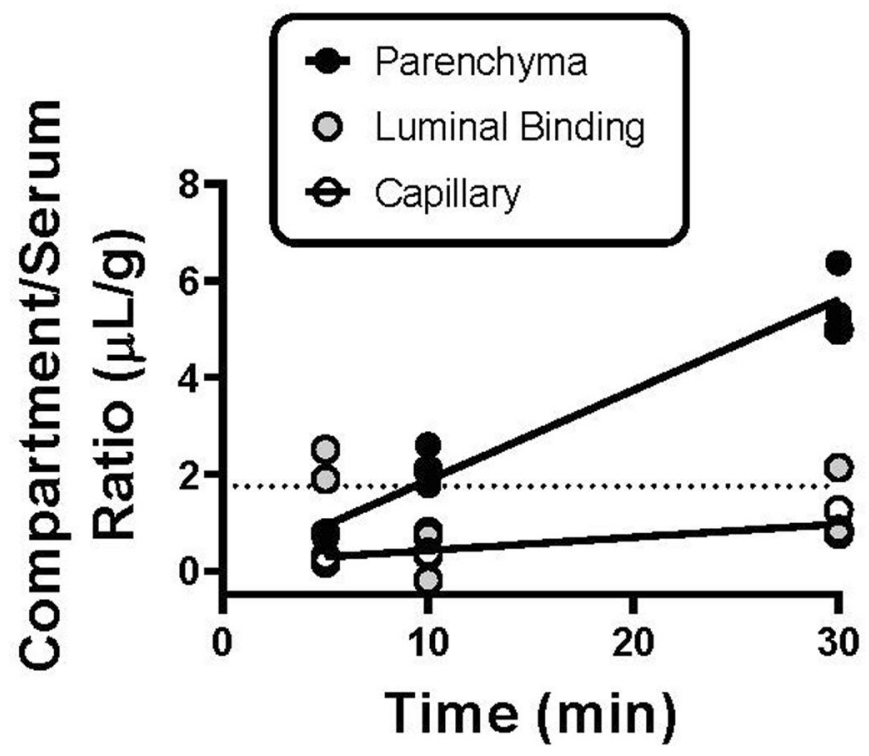

Extended Data Fig. 3 | Capillary depletion for I-S1. Capillary depletion studies were conducted to determine partitioning of the I-S1 (RayBiotech) in the capillary lumen, in the capillary, and in the brain parenchyma over time. The compartment that contained radioactivity was plotted against clock time, and the slopes were analyzed by linear regression. The slope of the line plotted for the parenchymal fraction was $0.187 \pm 0.016 \mu \mathrm{L} / \mathrm{g}$ - min, $r 2=0.952$, $n=9$ mice, and was non-zero ( $p<0.0001$ ); the slope for the capillary fraction was $0.027 \pm 0.006 \mu \mathrm{L} / \mathrm{g}$-min, $r 2=0.757, n=9$ mice, and was non-zero $(p=0.0023)$. The slope for luminal binding was $0.05041 \pm 0.04555 \mu \mathrm{L} / \mathrm{g}$ - $\mathrm{min}$ and did not significantly deviate from zero $(p=0.3050, n=9, r 2=0.145)$.The mean value for luminal binding over all time points was $1.75 \pm 0.50 \mu \mathrm{L} / \mathrm{g}$. 
a

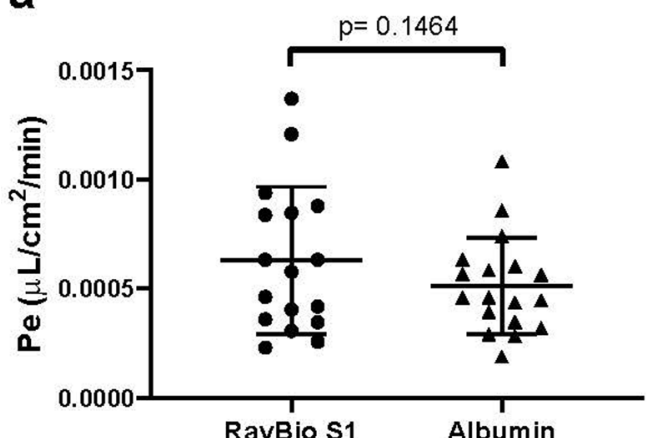

RayBio S1 Albumin

C

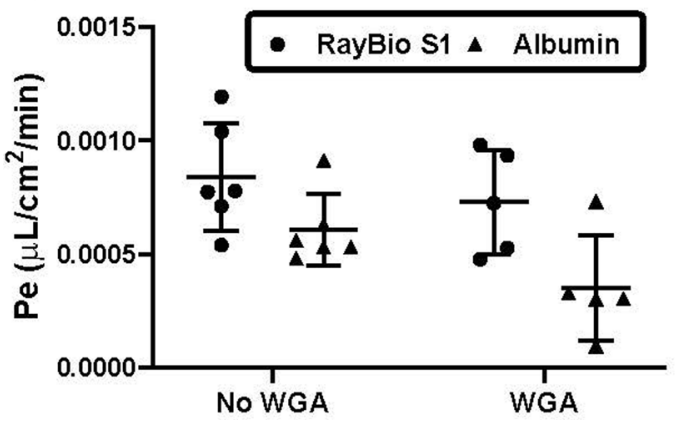

b

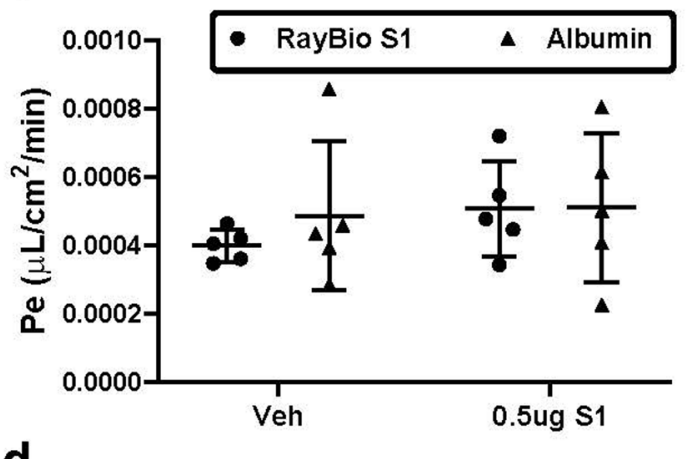

d

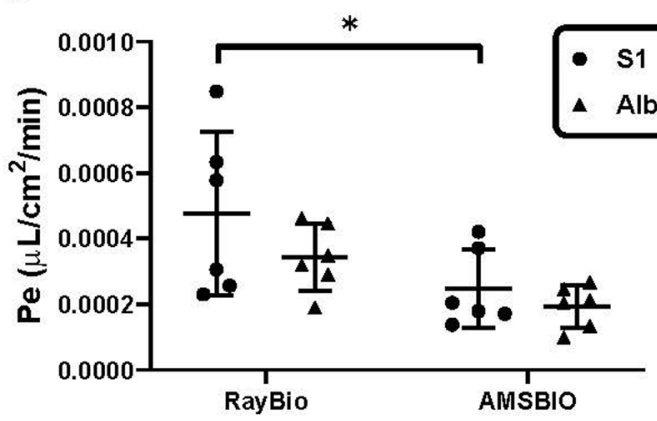

Extended Data Fig. 4 | Transport of S1 proteins across human iPSC-derived brain-like endothelial cell (iBEC) monolayers. a. RayBiotech I-S1 passage across the iBEC monolayer was not significantly faster than that of $\mathrm{T}$-Alb $(p=0.1464, t=1.527, \mathrm{df}=16$; two-tailed paired t-test). Combination of 3 independent differentiations, $\mathrm{n}=17$ transwells/group, average TEER $\left(2578 \pm 897.8 \Omega^{\star} \mathrm{cm} 2\right)$. b. Transport of RayBiotech I-S1 in the presence of $5 \mu \mathrm{g} / \mathrm{ml}$ excess unlabeled S1. Excess S1 had no significant effect on I-S1 or T-Albumin Pe ( $p>0.5$; two-way ANOVA). N=5-6 transwells/group from a single differentiation c. Transwells were treated with WGA $(0.5 \mathrm{mg} / \mathrm{ml})$ or vehicle. There was a significant overall effect of treatment $(F(1,9)=9.435$, $p=0.0133)$ and analyte $(F(1,9)=6.949, p=0.0271)$ on RayBiotech I-S1 or T-Alb transport (two-way ANOVA), but there were no significant effects of WGA on I-S1 or T-Alb Pe (Sidak's multiple comparisons testing). N=5-6 wells/group from a single differentiation. d. Comparison of RayBiotech I-S1 and AMSBIO I-S1 transport. T-Alb was included with each I-S1 and also compared to the I-S1. Two-way ANOVA showed differences between I-S1s from the two sources) $(F(1,10)=10.1, p=0.0098$ ], but not between analytes (T-Alb vs I-S1). Multiple comparisons using Sidak's test showed a faster transport for RayBiotech I-S1 vs AMSBIO I-S1 ( $p=0.0324)$. N =6 wells/group from a single differentiation ${ }^{\star} p<0.05$. 


\section{Reporting Summary}

Nature Research wishes to improve the reproducibility of the work that we publish. This form provides structure for consistency and transparency in reporting. For further information on Nature Research policies, see our Editorial Policies and the Editorial Policy Checklist.

\section{Statistics}

For all statistical analyses, confirm that the following items are present in the figure legend, table legend, main text, or Methods section.

$\mathrm{n} / \mathrm{a}$ Confirmed

$\bigotimes$ The exact sample size $(n)$ for each experimental group/condition, given as a discrete number and unit of measurement

$\square$ \ A statement on whether measurements were taken from distinct samples or whether the same sample was measured repeatedly

$\square$ The statistical test(s) used AND whether they are one- or two-sided

Only common tests should be described solely by name; describe more complex techniques in the Methods section.

$\bigotimes \square$ A description of all covariates tested

$\square$ A description of any assumptions or corrections, such as tests of normality and adjustment for multiple comparisons

$\varnothing$ A full description of the statistical parameters including central tendency (e.g. means) or other basic estimates (e.g. regression coefficient)

AND variation (e.g. standard deviation) or associated estimates of uncertainty (e.g. confidence intervals)

$\searrow$ For null hypothesis testing, the test statistic (e.g. $F, t, r$ ) with confidence intervals, effect sizes, degrees of freedom and $P$ value noted Give $P$ values as exact values whenever suitable.

Х $\square$ For Bayesian analysis, information on the choice of priors and Markov chain Monte Carlo settings

$\bigotimes \square$ For hierarchical and complex designs, identification of the appropriate level for tests and full reporting of outcomes

$\bigotimes \mid \square$ Estimates of effect sizes (e.g. Cohen's $d$, Pearson's $r$ ), indicating how they were calculated

Our web collection on statistics for biologists contains articles on many of the points above.

\section{Software and code}

Policy information about availability of computer code

$\begin{array}{ll}\text { Data collection No software used } & \\ \text { Data analysis } & \text { Prism } 8.0 \text { (GraphPad, Inc, San Diego CA) was used for data analysis }\end{array}$

For manuscripts utilizing custom algorithms or software that are central to the research but not yet described in published literature, software must be made available to editors and

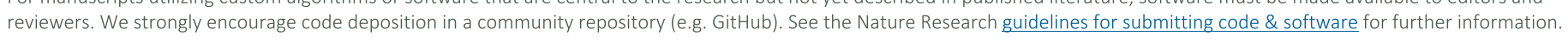

\section{Data}

Policy information about availability of data

All manuscripts must include a data availability statement. This statement should provide the following information, where applicable:

- Accession codes, unique identifiers, or web links for publicly available datasets

- A list of figures that have associated raw data

- A description of any restrictions on data availability

The data that support the findings of this study are available from the corresponding author upon reasonable request 
Please select the one below that is the best fit for your research. If you are not sure, read the appropriate sections before making your selection.

\ Life sciences

Behavioural \& social sciences

Ecological, evolutionary \& environmental sciences

For a reference copy of the document with all sections, see nature.com/documents/nr-reporting-summary-flat.pdf

\section{Life sciences study design}

All studies must disclose on these points even when the disclosure is negative.

Sample size Variance is known from previously conducting similar experiments and power at 0.8-0.9 based on 30-40\% differences between means

Data exclusions For multiple-time regression analysis, the method calls for exclusion of data points that contribute to non-linearity of the curve. Outliers whose exclusion improved the $\mathrm{r} 2>0.2$ were excluded from analysis. Excluded points are noted in Figures 2 and 3 by filled circles and further explained in those figure legends. For ANOVAs and comparisons of means, the Grubbs outlier exclusion test (alpha < 0.05 ) was applied once to detect single outliers, and any outliers that were excluded by this method are stated in the Figure legends and their values provided.

Replication Each figure was generated as a single experimental replicate, with the exception of iPSC studies where S1 and albumin transport were compared in three independent experiments. However, use of T-Alb as an internal control for all experiments allowed us to track consistency between experiments with different designs based on its predictable tissue/serum ratios. Further, the I-S1 tissue-serum ratios taken at the same time points from different experiments may be compared, and agree well with each other, demonstrating a reproducible observation of I-S1 transport into the brain and other tissues.

Randomization Anesthetized mice were randomized between test groups by alternating their assignments. Transwells were assessed for TEER prior to experiments and assigned to groups in such a way that TEER values between groups had approximately equal means and variances.

Blinding

Blinding was not done for experiments or analysis because this knowledge is required to carry out experiments and analysis.

\section{Reporting for specific materials, systems and methods}

We require information from authors about some types of materials, experimental systems and methods used in many studies. Here, indicate whether each material, system or method listed is relevant to your study. If you are not sure if a list item applies to your research, read the appropriate section before selecting a response.

\begin{tabular}{l|l} 
Materials \& experimental system \\
\hline$n / a$ & Involved in the study \\
\hline & $\square$ Antibodies \\
$\square$ Eukaryotic cell lines \\
$\square$ Palaeontology and archaeology \\
$\square$ & $\square$ Animals and other organisms \\
$\square$ & $\square$ Clinical data \\
$\square$ & $\square$ Dual use research of concern
\end{tabular}

Methods
\begin{tabular}{l|l} 
n/a & Involved in the study \\
$\square$ & $\square$ ChIP-seq \\
$\square$ & $\square$ Flow cytometry \\
$\square$ & $\square$ MRI-based neuroimaging
\end{tabular}

\section{Eukaryotic cell lines}

Policy information about cell lines

Cell line source(s)

Authentication

Mycoplasma contamination

Commonly misidentified lines (See ICLAC register)
GM25256 iPSC line from the Coriell Institute

Cells are routinely verified for iPSC markers such as Oct4, Nanog, and alkaline phosphatase

Cell lines were not tested for mycoplasma contamination in-house

Not applicable

\section{Animals and other organisms}

Policy information about studies involving animals; ARRIVE guidelines recommended for reporting animal research 
Wild animals

Wild animals were not used

Field-collected samples

Field-collected samples were not used.

Ethics oversight

Studies were approved by the institutional animal research review board and the facilities are approved by AAALAC

Note that full information on the approval of the study protocol must also be provided in the manuscript. 